\title{
The influence of exploration mode, orientation, and configuration on the haptic Müller-Lyer illusion
}

Morton A Heller, Melissa McCarthy, Jennifer Schultz, Jayme Greene, Melissa Shanley, Ashley Clark, Samantha Skoczylas, Jamie Prociuk

Department of Psychology, Physical Sciences Building, Eastern Illinois University, 600 Lincoln Avenue, Charleston, IL 61920, USA; e-mail: cfmah1@ux1.cts.eiu.edu

Received 5 May 2004, in revised form 17 January 2005; published online 19 October 2005

\begin{abstract}
We studied the impact of manner of exploration, orientation, spatial position, and configuration on the haptic Müller-Lyer illusion. Blindfolded sighted subjects felt raised-line Müller-Lyer and control stimuli. The stimuli were felt by tracing with the index finger, free exploration, grasping with the index finger and thumb, or by measuring with the use of any two or more fingers. For haptic judgments of extent a sliding tangible ruler was used. The illusion was present in all exploration conditions, with overestimation of the wings-out compared to wings-in stimuli. Tracing with the index finger reduced the magnitude of the illusion. However, tracing and grasping induced an overall underestimation of size. The illusion was greatly attenuated when stimuli were felt with the index fingers of both hands. Illusory misperception was not altered by the position in space of the Müller-Lyer stimuli. No effects of changes in the thickness of the line shaft were found, but there were effects of the length of the wing endings for the smaller, $5.1 \mathrm{~cm}$ stimuli. The theoretical and practical implications of the results are discussed.
\end{abstract}

\section{Introduction}

The Müller-Lyer illusion is powerful in both touch and in vision (see Heller et al 2002a). However, less is known about the factors that may influence the potency of illusions in touch, compared with vision. There have been far fewer studies of the Müller-Lyer illusion in haptics than in vision.

Haptic illusions are complex, and they could occur for a variety of reasons. These reasons may include the direction and rate of scanning movements in touch, the hand used to feel stimuli, configurational factors, errors in global size estimates, the regions of space within which stimuli are presented, and the body parts involved in feeling stimuli. Previous research has shown that it is even possible that lateralization could play a role in haptic illusions, as could gender (eg Heller et al 1997).

The Müller-Lyer illusion has been explained in terms of a confusion model (see Coren and Girgus 1978). On this view, the illusion derives from difficulty discriminating the wing endings from the lines themselves. Heller et al (2002a) reported evidence for a confusion model, since the strength of the haptic illusion was magnified with more acute wing angles (Carrasco et al 1986; Predebon 1996). Subjects should have more difficulty telling where the horizontal line shaft ends and the wings begin with more acute wing angles. Many explanations of the visual Müller-Lyer illusion have assumed that mistaken impressions of depth are responsible (Fisher 1970), but the haptic illusion occurs in congenitally blind persons (Heller et al 2002a).

An alternative interpretation of the haptic Müller-Lyer illusion was provided by Millar and Al-Attar (2002). According to Millar and Al-Attar, the illusion derives from discrepant information from the wings and shaft of the figures. Thus, the illusion was practically eliminated when subjects were instructed to use their bodies as a reference to code stimulus extent. This instruction prompted an egocentric method of coding, thereby reducing the magnitude of illusory misperception. Their results were consistent with the idea that adding reliable spatial-reference information may reduce the effect of discrepant cues to length. 
Most sighted subjects spontaneously use tracing with the index finger when feeling raised-line forms (Symmons and Richardson 2000), but this may not be an optimal strategy. Recently, however, many blind subjects objected to the use of one finger for tracing lines in studies of haptic illusions, and thought that they would be able to make more accurate judgments of extent using grasping or multiple fingers (eg Heller et al 2002a, 2002b, 2003b, 2004). One might predict that illusory misperception could derive from the adoption of poor exploration strategies, especially by subjects unskilled in the use of touch (see Gibson 1966, 1979; Heller et al 2004). The haptic horizontalvertical illusion was diminished in strength when subjects explored solid stimuli using tracing (Heller et al 2003a). Furthermore, the haptic horizontal-vertical illusion was greatly attenuated when subjects explored stimuli using finger motion alone and movement of the entire arm was eliminated by the use of splints (Heller et al 1997). However, these results may not generalize to a different illusory configuration.

The present study was partially motivated by an interest in determining if the Müller-Lyer illusion is affected by experimental manipulations in a similar manner as in the horizontal-vertical illusion. Gentaz and Hatwell (2004) argued that exploration mode had a major effect on haptic exploration in the horizontal-vertical illusion, but not the Müller-Lyer illusion. They thought that the Müller-Lyer illusion was present in both vision and touch, and was influenced by similar processes. We sought to determine if the haptic Müller-Lyer illusion would disappear with the use of alternative methods for feeling stimuli, as has been shown to be the case for the horizontalvertical illusion. Thus, we expected that the Müller-Lyer illusion would diminish in strength when subjects were allowed free exploration.

Non-optimal stimulus presentation conditions could serve to magnify perceptual errors, or even reverse them (see Heller 1992; Heller et al 1997). On this view, illusory misperception might be reduced through placement in the frontal plane, since this has been reported for the horizontal-vertical illusion (Heller et al 2003a). Placement flat on the table top may not be optimal for haptic perception of extent.

The research strategy of the present study involved the use of converging methods to attempt to understand the mechanisms responsible for the Müller-Lyer illusion in touch. Conceivably, the same manipulations that alter the illusion in vision could alter them in touch. Alternatively, different causal mechanisms could be at work (see Gentaz and Hatwell 2004). If so, one might see different patterns of results from the same experimental manipulations than those obtained in vision or in other haptic illusions. For example, frontal placement has a very different impact on the haptic horizontalvertical illusion than it has on the visual illusion. Frontal placement yielded a reversal of the 'normal' horizontal-vertical illusion, with overestimation of horizontals rather than verticals. This result indicated that the horizontal-vertical illusion is affected by gravitational placement very differently in touch than in vision, since frontal placement does not have this effect on the visual illusion. It was not known if the haptic MüllerLyer illusion would be affected by frontal placement. However, there are good reasons for believing that it might be influenced by this position in space, since it could magnify gravitational cues. This could aid haptics in some instances, especially if this position yielded improved spatial-reference information. This would follow on the theoretical assumption that we normally interpret patterns in terms of spatial coordinate reference frames. In some circumstances, this reference frame could derive from our bodies or from external cues (see Millar 1994).

The object of experiments 1 and 2 was to examine the effect of exploration mode on the haptic Müller-Lyer illusion; that of experiment 3 was to test the effect of position in space and orientation on the illusion, since these factors are known to have major effects on the expression of the haptic horizontal-vertical illusion. Other experiments were designed to test confusion models of the haptic Müller-Lyer illusion, since 
Heller et al (2002a) reported evidence for a confusion explanation. Alterations in the angles of the wing endings modified the strength of the illusion (Over 1966), and it was thought that changes in the thickness of the line shaft and length of the wings might also yield similar effects. These manipulations were designed to alter the ease of discriminating the lines from the wing endings, with increases in discriminability likely to yield reductions in the strength of the illusion. However, the earlier study of the effect of wing angle on the illusion did not control for the overall size of the patterns. Stimuli with more acute wing angles in Heller et al (2002a) yielded stronger illusory misperception, but wing length was held constant. This meant that the stimuli with more acute angles were also longer. The obtained effect of wing angle could have been a consequence of larger global size, rather than wing angle, per se. This would be expected to occur in haptics as in vision. It could be expected that the illusion would be attenuated given increases in the thickness of the line shaft (experiment 5). Increases in the length of the wings (experiment 6) might be expected to magnify the illusion, if subjects respond to the global size of the stimuli. Alternatively, smaller wings might be more difficult to discriminate from the shaft and could alter the strength of the illusion in the opposite direction.

\section{Experiment 1: The influence of exploration mode on the haptic illusion}

In the first experiment, we tested the influence of exploration mode on the haptic Müller-Lyer illusion. Subjects were allowed free exploration, or their haptic examination was restricted in a variety of ways. It was expected that the illusion would be attenuated with free exploration, on the assumption that limiting haptic exploration would reduce the accuracy of judgments of extent (see Jansson and Monaci 2004).

\subsection{Method}

2.1.1 Subjects. There were twelve subjects in each of four groups $(N=48)$. Half of the subjects were male and half were female. All of the subjects in all of the experiments reported here were strongly right-handed. The subjects were identified as right-handed in this and subsequent experiments reported here if they responded "right hand" to all questions on a questionnaire [derived from Millar's behavioral tests (1984)] asking which hand they used for the following activities: writing, drawing, throwing a ball, cutting with scissors, using a soup spoon, and brushing teeth. The subjects were randomly assigned to the groups.

2.1.2 Stimuli and apparatus. The Müller-Lyer stimuli were 2.5, 5.1, 7.6, and $10.2 \mathrm{~cm}$ long, and produced on swell-paper. Figure 1 shows the stimuli, including wings-in and wingsout Müller-Lyer patterns, control plain lines, and control lines with vertical ends. We did not use the Brentano form of the illusion; other researchers have used similar control

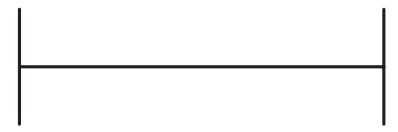

(a)

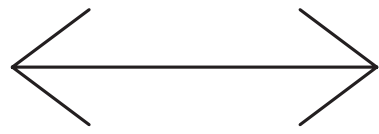

(c) (b)

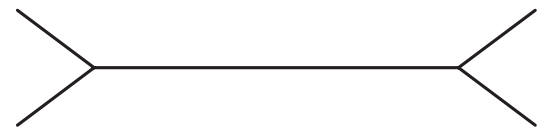

(d)

Figure 1. Stimuli in the experiment: (a) control plain line; (b) control line with vertical ends; (c) 'wings-in' stimulus; (d) 'wings-out' stimulus. 


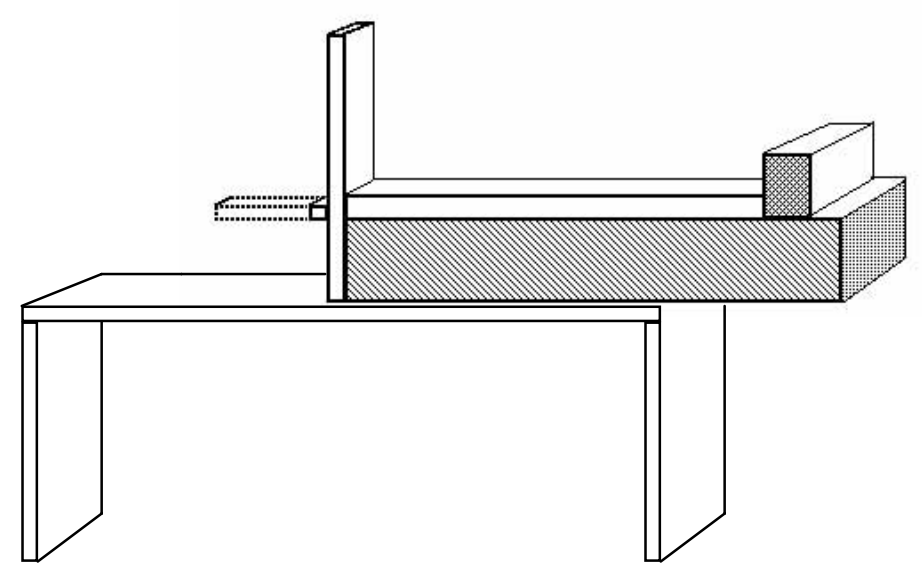

Figure 2. The haptic sliding ruler. The ruler was elevated upon a shelf, and the stimuli were placed beneath it. This allowed the subjects to feel the stimulus with their right index fingers and make size estimates with their left hands.

stimuli (Carrasco et al 1986). Subjects were exposed to 2 trials at each size. The included angle of the wings was $70^{\circ}$, and the lines that comprised the endings were $1.4 \mathrm{~cm}$ long. Size estimates were obtained with an adjustable tangible ruler (see figure 2; Heller et al 2002a). The procedure was similar to that of Heller et al (2002a), with the exception of the use of additional exploration methods; previous research limited subjects to haptics and tracing with the index finger of one hand. Subjects could not see their hands or the tangible ruler in experiments $1-6$ of the present study, since they were blindfolded throughout. The markings on the tangible ruler were visible (only to the experimenter), but could not be felt. The experimenters viewed the numbers on the rulers and recorded the haptic size estimates. Size was included as a stimulus variable in the present study, since it has been shown to be important for other haptic illusions (Heller et al 2003a, 2004).

2.1.3 Design and procedure. The experiment was a between - within design, with independent groups for exploration method (tracing, free exploration, grasping, or measuring), with repeated measures on type of line ending (wings in, wings out, plain lines, lines with vertical ends), line length (4), and trials (2). There were four independent groups. Subjects in one group traced the patterns with their right index fingers and made haptic size estimates with their left hands using the tangible ruler. Subjects in a second, freeexploration group were allowed to feel the tangible lines in any manner they wished, but only with their right hands. The measuring group subjects were told to use any two or more fingers of their right hands to feel the lines, and the grasping subjects were limited to the use of the index finger and thumb of the right hand. All subjects were instructed to feel the lines and endings, but were told to "only judge the length of the line that goes from side to side". They were instructed that they should not include the wing endings in their estimates of the lengths of the lines for the wings-out stimuli. No time limits were imposed and subjects were not given any feedback about their judgments. They were told that they could feel the tangible ruler in any way that they wished, but only with their left hands. Subjects were told to pull the ruler out from the panel so that its extension equaled the length of the lines that they were judging.

We did not record the number of times subjects felt the lines, or the strategies that were used in the free-exploration condition. Thus, it is possible that subjects traced the lines different numbers of times in the different conditions of this experiment, but all subjects were allowed as much time as they wished. 
Subjects experienced the different types of lines in blocks of trials, with all sizes within each trial block, and 2 trials for each size. The order of presentation of trial blocks was randomized. Further details about the design can be found in Heller et al (2002a).

\subsection{Results and discussion}

Table 1 summarizes the results of the experiment and shows a strong Müller-Lyer illusion. Wings-out patterns were judged as longer than wings-in stimuli. The control stimuli, with plain lines or lines with vertical endings, were judged as intermediate in length.

An ANOVA on mean size estimates indicated a non-significant effect of exploration mode $\left(F_{3,44}=2.58, p=0.07\right)$. The effect of line ending was significant, owing to a strong illusion $\left(F_{3,132}=59.43, p=0.00\right)$. A Newman-Keuls test showed that wings-in stimuli $(M=5.5 \mathrm{~cm})$ were judged as shorter than the other stimuli, and wings-out

Table 1. Mean size judgments, mean signed error scores (in brackets, beneath mean size judgments), and percentage illusion strength for the Müller-Lyer illusion as a function of exploration mode, figure, and size (standard deviations in parentheses). Illusion-strength score is computed by taking the wings out minus wings in, divided by the standard, true size.

\begin{tabular}{|c|c|c|c|c|c|}
\hline \multirow{2}{*}{$\begin{array}{l}\text { Actual stimulus } \\
\text { size } / \mathrm{cm}\end{array}$} & \multicolumn{4}{|c|}{ Mean size judgment of stimulus/cm } & \multirow{2}{*}{$\begin{array}{l}\text { Illusion } \\
\text { strength/\% }\end{array}$} \\
\hline & wings in & wings out & $\begin{array}{l}\text { vertical } \\
\text { ends }\end{array}$ & $\begin{array}{l}\text { plain } \\
\text { lines }\end{array}$ & \\
\hline \multicolumn{6}{|l|}{ Free exploration } \\
\hline 2.5 & $\begin{array}{l}2.1(0.6) \\
{[-0.4]}\end{array}$ & $\begin{array}{l}3.6(0.9) \\
{[1.1]}\end{array}$ & $\begin{array}{l}2.6(0.4) \\
{[0.1]}\end{array}$ & $\begin{array}{l}2.6(0.4) \\
{[0.05]}\end{array}$ & 60.0 \\
\hline 5.1 & $\begin{array}{l}4.6(0.8) \\
{[-0.5]}\end{array}$ & $\begin{array}{l}6.0(1.3) \\
{[0.9]}\end{array}$ & $\begin{array}{l}4.9(0.5) \\
{[-0.3]}\end{array}$ & $\begin{array}{l}5.2(0.8) \\
{[0.1]}\end{array}$ & 27.5 \\
\hline 7.6 & $\begin{array}{l}6.9(1.6) \\
{[-0.7]}\end{array}$ & $\begin{array}{l}8.3(1.5) \\
{[0.7]}\end{array}$ & $\begin{array}{l}7.3(1.4) \\
{[-0.3]}\end{array}$ & $\begin{array}{l}7.5(1.1) \\
{[-0.1]}\end{array}$ & 18.4 \\
\hline 10.2 & $\begin{array}{l}8.4(2.1) \\
{[-1.8]}\end{array}$ & $\begin{array}{c}9.9(2.0) \\
{[-0.3]}\end{array}$ & $\begin{array}{l}9.1(1.4) \\
{[-1.1]}\end{array}$ & $\begin{array}{l}9.5(1.4) \\
{[-0.7]}\end{array}$ & 14.7 \\
\hline \multicolumn{6}{|l|}{ Tracing } \\
\hline 2.5 & $\begin{array}{l}2.3(0.7) \\
{[-0.2]}\end{array}$ & $\begin{array}{l}3.4(0.9) \\
{[0.9]}\end{array}$ & $\begin{array}{l}3.1(0.7) \\
{[0.6]}\end{array}$ & $\begin{array}{l}2.8(0.7) \\
{[0.3]}\end{array}$ & 44.0 \\
\hline 5.1 & $\begin{array}{l}4.3(1.5) \\
{[-0.8]}\end{array}$ & $\begin{array}{l}4.7(1.2) \\
{[-0.4]}\end{array}$ & $\begin{array}{l}5.7(1.0) \\
{[-1.0]}\end{array}$ & $\begin{array}{l}4.6(1.2) \\
{[-0.5]}\end{array}$ & 7.8 \\
\hline 7.6 & $\begin{array}{l}6.0(1.8) \\
{[-1.6]}\end{array}$ & $\begin{array}{l}6.6(1.7) \\
{[-1.0]}\end{array}$ & $\begin{array}{l}6.0(1.6) \\
{[-1.6]}\end{array}$ & $\begin{array}{l}6.2(1.7) \\
{[-1.4]}\end{array}$ & 7.9 \\
\hline 10.2 & $\begin{array}{l}7.6(2.1) \\
{[-2.6]}\end{array}$ & $\begin{array}{l}8.0(2.0) \\
{[-2.2]}\end{array}$ & $\begin{array}{l}7.5(2.5) \\
{[-2.7]}\end{array}$ & $\begin{array}{l}8.0(2.3) \\
{[-2.2]}\end{array}$ & 3.9 \\
\hline \multicolumn{6}{|l|}{ Measuring } \\
\hline 2.5 & $\begin{array}{l}2.2(0.6) \\
{[-0.3]}\end{array}$ & $\begin{array}{l}4.5(1.3) \\
{[2.0]}\end{array}$ & $\begin{array}{l}3.1(1.0) \\
{[0.6]}\end{array}$ & $\begin{array}{l}3.0(0.6) \\
{[0.5]}\end{array}$ & 92.0 \\
\hline 5.1 & $\begin{array}{l}4.9(1.0) \\
{[-0.2]}\end{array}$ & $\begin{array}{l}6.4(1.2) \\
{[1.3]}\end{array}$ & $\begin{array}{l}5.3(1.7) \\
{[0.3]}\end{array}$ & $\begin{array}{l}5.7(1.0) \\
{[0.6]}\end{array}$ & 29.4 \\
\hline 7.6 & $\begin{array}{l}7.3(1.4) \\
{[-0.3]}\end{array}$ & $\begin{array}{l}8.9(1.6) \\
{[1.3]}\end{array}$ & $\begin{array}{l}8.0(1.7) \\
{[0.4]}\end{array}$ & $\begin{array}{l}8.0(1.2) \\
{[0.4]}\end{array}$ & 21.1 \\
\hline 10.2 & $\begin{array}{l}9.1(1.5) \\
{[-1.1]}\end{array}$ & $\begin{array}{l}10.9(2.0) \\
{[0.7]}\end{array}$ & $\begin{array}{l}9.5(1.6) \\
{[0.7]}\end{array}$ & $\begin{array}{l}10.3(1.9) \\
{[0.1]}\end{array}$ & 17.6 \\
\hline \multicolumn{6}{|l|}{ Grasping } \\
\hline $2.5^{\circ}$ & $\begin{array}{l}2.2(0.9) \\
{[-0.3]}\end{array}$ & $\begin{array}{l}4.0(1.5) \\
{[1.5]}\end{array}$ & $\begin{array}{l}2.7(0.9) \\
{[0.2]}\end{array}$ & $\begin{array}{l}2.1(0.8) \\
{[-0.4]}\end{array}$ & 72.0 \\
\hline 5.1 & $\begin{array}{l}4.7(1.6) \\
{[-0.4]}\end{array}$ & $\begin{array}{l}6.1(1.9) \\
{[1.0]}\end{array}$ & $\begin{array}{l}4.7(1.3) \\
{[-0.6]}\end{array}$ & $\begin{array}{l}4.5(1.5) \\
{[-0.6]}\end{array}$ & 27.5 \\
\hline 7.6 & $\begin{array}{l}6.8(1.9) \\
{[-0.8]}\end{array}$ & $\begin{array}{l}7.8(2.0) \\
{[0.2]}\end{array}$ & $\begin{array}{l}6.7(1.5) \\
{[-1.0]}\end{array}$ & $\begin{array}{l}6.4(1.5) \\
{[-1.2]}\end{array}$ & 13.2 \\
\hline 10.2 & $\begin{array}{l}8.3(2.1) \\
{[-2.0]}\end{array}$ & $\begin{array}{c}9.9(2.2) \\
{[-0.3]}\end{array}$ & $\begin{array}{l}8.6(1.7) \\
{[-1.6]}\end{array}$ & $\begin{array}{l}8.4(1.8) \\
{[-1.8]}\end{array}$ & 15.7 \\
\hline
\end{tabular}


patterns $(M=6.8 \mathrm{~cm})$ were judged as longer $(p<0.05)$. The control stimuli yielded size estimates that were similar to each other, and the lines with vertical endings $(M=5.8 \mathrm{~cm})$ were not significantly different from plain lines $(M=5.9 \mathrm{~cm})$. However, the interaction between exploration mode and type of line ending was highly significant $\left(F_{9,132}=3.92, p<0.001\right)$. The illusion was diminished, but not eliminated, by tracing with the fingertip. Even with tracing, there was a positive illusion for the smallest stimuli. The simple effect of the type of line ending was significant for all exploration modes (all $p \mathrm{~s}<0.025$ ), but the simple effect of exploration mode had no effect on wings-in patterns $(F<1)$. Furthermore, tracing yielded much smaller overall judgments of line length (as compared with the objective sizes of the lines) than the other exploration strategies (see table 1). ${ }^{(1)}$ There was also a significant interaction between mode and trials $\left(F_{3,44}=3.02, p<0.05\right)$. The effect of mode was significant on the second trial $(p<0.05)$, but not on the first trial $(p>0.10)$. The trials effect was linked to measuring $(p<0.05)$, where mean size estimates increased from the first trial $(M=6.48 \mathrm{~cm})$ to the second trial $(M=6.90 \mathrm{~cm})$.

A separate analysis included gender as a variable but it failed to reach significance $(F<1)$; all of the interactions with gender were non-significant (all $p$ s $>0.25$ ); consequently, gender was not included as a variable in subsequent analyses.

One reviewer wondered if the subjects could be using some sort of timing strategy while tracing, such as counting. Conceivably, they could count while tracing the line shaft and also count while moving the ruler. However, a number of subjects were observed to engage in tracing the line shaft and the ruler at the same time. They used the index finger of the left hand to trace the ruler, after moving it out. Thus, a number of subjects were observed engaging in simultaneous tracing of the ruler with the left index finger and the line with the right index finger. Subsequently, these subjects made further ruler adjustments if it became clear to them that they were underestimating or overestimating the length of the line.

Tracing shorter Müller-Lyer stimuli did not completely eliminate the illusion (see table 1). As indicated by percentage illusion strength (wings out minus wings in divided by the standard), the illusion was still potent with tracing, at $44 \%$ for the $2.5 \mathrm{~cm}$ stimuli, but only about $4 \%$ for the largest stimuli. Note that the use of percentage illusion as a measure of the illusion strength of the Müller-Lyer illusion may actually underestimate or overestimate the strength of the illusion if there is some sort of systematic bias in length judgments. There was some cost of the reduction of the strength of the illusion in terms of distortion of overall line length with tracing. This issue is examined more fully in a later experiment, since subjects may judge horizontally placed stimuli as smaller or larger than they really are. They did this in the present experiment, and so it may be appropriate to consider the straight lines and lines with vertical endings as the relevant controls. Nonetheless, the use of percentage illusion, by making use of the standard true lengths, provides a very convenient way to describe the strength of the illusion.

The results also indicate that we should be cautious about uncritically accepting introspective reports by visually impaired or sighted people (eg Heller et al 2002a, 2002b). Blind people often object to the use of one finger for feeling patterns. They routinely recommended the use of multiple fingers of one hand. Nonetheless, when a (1) In previous research, raised-line drawing kits were used, and it was considered possible that the swell-paper might induce underestimation (Heller et al 2002). Texture could influence judgments of length, and so line length judgments of lines produced on swell-paper were compared with those of lines drawn with the raised-line drawing kit. The raised-line drawing kit yields lines that have a bumpy surface. The effect of material was highly significant $\left(F_{1,11}=6.1, p<0.05\right)$ with longer mean judgments for the smoother swell-paper lines $(M=5.8 \mathrm{~cm})$ than the lines produced with the raised-line drawing kit $(M=5.4 \mathrm{~cm})$. Swell-paper did not induce a general bias towards underestimation of line length. 
single hand is used, tracing with the index finger is not necessarily a poor method for haptic exploration of line length.

A separate analysis was conducted on the signed error scores, and the results were similar in most respects to the main analysis reported on the size judgments. The presence of the illusion was shown by a significant effect of type of line ending $\left(F_{3,132}=56.75, p<0.001\right)$. Mean signed error scores for the wings in, wings out, lines with vertical endings, and plain lines were $-0.868,+0.451,-0.541$, and -0.418 , respectively. Wings-in patterns were underestimated and wings-out patterns were overestimated with reference to the objective size of the stimuli. The main effect of exploration mode failed to reach significance $\left(F_{3,44}=2.64, p=0.061\right)$. There was a significant effect of size $\left(F_{3,132}=55.5, p<0.01\right)$, and a significant interaction between exploration mode and size $\left(F_{9,132}=4.0, p<0.001\right)$. The simple effect of exploration mode was only significant for the $7.6 \mathrm{~cm}$ and $10.2 \mathrm{~cm}$ stimuli (both $p \mathrm{~s}<0.01$ ). This reflects the great impact of mode of exploration on the larger stimuli. Furthermore, there was a significant interaction between exploration mode and type of line ending $\left(F_{9,132}=3.68\right.$, $p<0.001)$. Exploration mode had no effect on wings-in patterns, but type of line ending had significant effects for all exploration modes (all $p \mathrm{~s}<0.025)$. The interaction derived from a different pattern of mean signed error scores $\left(M_{\mathrm{se}} \mathrm{s}\right)$ for tracing, where wings-out patterns were judged as smaller than their objective size $\left(M_{\mathrm{se}}=-0.681\right)$, but larger than the wings-in stimuli $\left(M_{\mathrm{se}}=-1.288\right)$. This was unlike all other exploration modes, where the wings-out patterns yielded positive signed error scores. The interaction between wing endings and size was significant $\left(F_{9,396}=3.67, p<0.001\right)$, but all of the tests of the simple effects of this interaction were also significant (all $p$ s $<0.01)$. The main effect of trials failed to reach significance $(F<1)$, as did the interaction between trials and size $(p=0.06)$. The lack of a main effect of trials may be the result of the use of only 2 trials at each size. Practice has been shown to lead to a decrement in the illusion, but generally with rather large numbers of trials (see Dewar 1967; Rudel and Teuber 1963). Note that the subjects showed systematic underestimation of the control lines, since they were judged as smaller than they really were (see table 1). This could have been a consequence of their horizontal orientation, and so this variable was examined in experiment 3.

One reviewer suggested that having subjects also experience control lines, the plain lines, and the lines with vertical endings, could have influenced the judgments of the Müller-Lyer stimuli. However, none of the subjects was aware of the relationship of the lengths of control lines and the Müller-Lyer stimuli. In addition, previous research yielded a haptic Müller-Lyer illusion (Heller et al 2002a) whether or not the control stimuli were present. The illusion was also found in experiment 6 of this study, without the presence of the control stimuli.

\section{Experiment 2: Exploration with the index fingers of both hands}

Some of the data from experiment 1 were presented at the 'Psychonomics' meeting in Vancouver (Heller et al 2003b). A couple of astute individuals suggested that the haptic illusion would be diminished, perhaps eliminated, by feeling the Müller-Lyer stimuli with the two index fingers. This suggestion led to the present experiment. Of course, there are a number of reasons why the use of two hands could diminish the illusion and prompt accurate perception of length. Ballesteros and her colleagues (Ballesteros et al 1997, 1998) showed that symmetry judgments were aided by the use of two hands during haptic exploration. The use of two hands could assist haptic perception of extent, by providing an egocentric spatial reference frame for exploration (see Millar 1994). In addition, the use of two hands is known to help with reading Braille (see Millar 1997). It was expected that the haptic Müller-Lyer illusion would be much weaker when subjects were restricted to exploration with two index fingers. 


\subsection{Method}

3.1.1 Subjects. Twelve naive subjects participated in this experiment (six male, six female).

3.1.2 Stimuli and apparatus. The stimuli and apparatus were similar to those of the earlier experiments. Subjects felt swell-paper stimuli with wings in, wings out, plain lines, and lines with vertical ends. The stimuli were of the same size as in experiment 1 .

3.1.3 Procedure. The design and procedure were very much like those of the earlier experiment, except that participants were restricted to the use of both index fingers to feel the raised-line patterns produced on swell-paper. They were told to avoid using both fingers together in a tracing manner, and were to move them from the middle of each stimulus outward toward the ends. This instruction was designed to prevent subjects from merely tracing stimuli with a functionally 'large index finger' derived from tracing with two adjacent index fingers at once. The stimuli were always presented at the same location at the body midline. As in the first experiment reported here, the blindfolded subjects were told to feel the wings at the ends of the horizontal patterns, but were not to include the wings-out line endings in their length judgments. The same tangible ruler of experiment 1 was used for size judgments. The participants used their left hands to adjust the ruler.

\subsection{Results and discussion}

Table 2 shows the results of the experiment and indicates a greatly weakened illusion. An ANOVA on the type of line ending indicated that the effect of line ending was significant $\left(F_{3,33}=2.9, p<0.05\right)$. The mean for the wings-out Müller-Lyer stimuli $(M=5.61 \mathrm{~cm})$ was larger than the other means, but the rest of the stimuli were all judged as very similar in size. This reflects a reduction in the strength of the illusion with the use of two index fingers. The mean size judgments for the wings in, plain lines, and lines with vertical endings were $5.24,5.22$, and $5.21 \mathrm{~cm}$, respectively. Despite the significant main effect of type of ending, a Newman-Keuls test on the mean judged size for the different line endings failed to indicate any significant differences between the means (all $p \mathrm{~s}>0.05)$. The effect of size was highly significant $\left(F_{3,33}=151.0\right.$, $p<0.001)$, but the interaction between size and trials failed to reach significance $\left(F_{3,33}=2.43, p>0.08\right)$. None of the other main effects or interactions reached significance (all $p \mathrm{~s}>0.10)$.

A second ANOVA on signed error scores yielded results that were consistent with the ANOVA on mean size estimates. Mean signed error scores for the wings in, wings out, plain lines, and lines with vertical ends were $-1.114,-0.745,-1.130$, and -1.140 , respectively.

Table 2. Mean size judgments, mean signed error scores (in brackets, beneath mean size judgments), and percentage illusion strength for the Müller-Lyer illusion as a function of figure and size (with standard deviations in parentheses) for touching with two index fingers in experiment 2.

\begin{tabular}{|c|c|c|c|c|c|}
\hline \multirow{2}{*}{$\begin{array}{l}\text { Actual stimulus } \\
\text { size } / \mathrm{cm}\end{array}$} & \multicolumn{4}{|c|}{ Estimated length of stimulus/cm } & \multirow{2}{*}{$\begin{array}{l}\text { Illusion } \\
\text { strength } / \%\end{array}$} \\
\hline & wings in & wings out & $\begin{array}{l}\text { vertical } \\
\text { ends }\end{array}$ & $\begin{array}{l}\text { plain } \\
\text { lines }\end{array}$ & \\
\hline 2.5 & $\begin{array}{l}2.35(0.52) \\
{[-0.15]}\end{array}$ & $\begin{array}{l}2.89(0.68) \\
{[0.39]}\end{array}$ & $\begin{array}{l}2.48(0.46) \\
{[-0.03]}\end{array}$ & $\begin{array}{l}2.75(0.63) \\
{[0.25]}\end{array}$ & 21.6 \\
\hline 5.1 & $\begin{array}{l}4.38(0.74) \\
{[-0.72]}\end{array}$ & $\begin{array}{l}4.68(0.95) \\
{[-0.42]}\end{array}$ & $\begin{array}{l}4.27(0.91) \\
{[-0.83]}\end{array}$ & $\begin{array}{l}4.48(1.01) \\
{[-0.62]}\end{array}$ & 5.9 \\
\hline 7.6 & $\begin{array}{l}6.06(1.12) \\
{[-1.54]}\end{array}$ & $\begin{array}{l}6.55(1.46) \\
{[-1.05]}\end{array}$ & $\begin{array}{l}6.15(1.41) \\
{[-1.45]}\end{array}$ & $\begin{array}{l}6.08(1.28) \\
{[-1.52]}\end{array}$ & 6.4 \\
\hline 10.2 & $\begin{array}{l}8.16(1.67) \\
{[-2.04]}\end{array}$ & $\begin{array}{l}8.30(2.05) \\
{[-1.90]}\end{array}$ & $\begin{array}{l}7.95(2.11) \\
{[-2.25]}\end{array}$ & $\begin{array}{l}7.56(1.70) \\
{[-2.64]}\end{array}$ & 1.4 \\
\hline
\end{tabular}


As in the main analysis on size estimates, the Newman-Keuls test indicated that the means were not significantly different, $p>0.05$. The only significant difference in the ANOVA on signed error scores consisted of a significant interaction effect between size and trials $\left(F_{3,33}=3.50, p<0.05\right)$. The interaction derived from a failure to find an effect of trials for the $7.5 \mathrm{~cm}$ stimuli $(p=0.24)$.

Clearly, the use of two fingers weakened the illusion, and any residual illusory distortion consisted of a very slight relative overestimation (about $4 \mathrm{~mm}$ ) of the wingsout patterns. Wings-in Müller-Lyer patterns were judged as similar in size to the control stimuli. In terms of the percentage illusion-strength (PI) scores, the illusion was larger for the $2.5 \mathrm{~cm}$ stimuli $(\mathrm{PI}=21.6 \%)$ than for the $5.1 \mathrm{~cm}$ stimuli $(\mathrm{PI}=5.9 \%)$ and the $7.6 \mathrm{~cm}$ stimuli $(\mathrm{PI}=6.4 \%)$, but it was almost nonexistent for the largest $(10.2 \mathrm{~cm})$ stimuli $(\mathrm{PI}=1.4 \%)$. The present results are consistent with an early report by Hatwell (1960) that the use of free exploration and two hands reduced the magnitude of the Müller-Lyer illusion.

The use of two fingers may have made it easier for subjects to feel where the patterns ended for the wings-in Müller-Lyer figures. The slight overestimation of the wingsout patterns could have reflected a minimal tendency to respond to the global shapes of the patterns.

Subjects using two fingers of one hand to grasp patterns showed a strong MüllerLyer illusion in experiment 1 , but the use of the index fingers of two hands weakened the illusion in this experiment. The use of two hands is a natural way to illustrate size, but this may not be the case for two fingers of one hand.

In an attempt to better understand the possible differences between grasping with the index finger and thumb and bimanual use of two index fingers, the size estimate data from experiment 2 were compared with those from the grasping group of experiment 1 . A between - within ANOVA yielded a non-significant main effect of exploration mode $\left(F_{1,22}=1.22, p>0.05\right)$, and a robust effect of line ending $\left(F_{3,66}=28.18, p<0.001\right)$. A Newman-Keuls test on the means for the different line endings showed that the wings-out patterns $(M=6.28 \mathrm{~cm})$ were judged as significantly longer than all of the other means $(p<0.01)$, but the wings-in figures $(M=5.37 \mathrm{~cm})$ did not differ significantly $(p>0.05)$ from the plain lines $(M=5.29 \mathrm{~cm})$ or the lines with vertical endings $(M=5.45 \mathrm{~cm})$; the other means were not significantly different from each other $(p>0.05)$. Thus, the illusion was limited to overestimation of the wings-out stimuli.

There was also a significant interaction between type of line ending and exploration method $\left(F_{3,66}=9.76, p<0.001\right)$. Tests of the simple effects of this interaction showed that exploration method mattered only for wings-out patterns $(p<0.02)$, but not for the other line endings (for all $p>0.39$ ). The effect of type of line ending was highly significant for grasping $\left(F_{3,66}=35.5, p<0.01\right)$, but the simple effect of type of line ending failed to reach significance for touching with the two index fingers $\left(F_{3,66}=2.46, p>0.07\right)$. Thus, the use of the two index fingers greatly attenuated and practically eliminated the illusion, while grasping with the index finger and thumb magnified illusory misperception of the Müller-Lyer patterns.

A significant main effect of trials reflected the finding that stimuli were judged as longer on the first trial $(M=5.76 \mathrm{~cm})$ than the second trial $(M=5.44 \mathrm{~cm})(p<0.05)$. A size by trials interaction was significant $\left(F_{3,66}=4.58, p<0.01\right)$, but a test of simple effects of this interaction showed that the effect of trials was limited to the largest $10.2 \mathrm{~cm}$ stimuli $\left(F_{1,22}=7.74, p=0.01\right.$; all other tests of the simple effect of trials yielded ps $>0.08)$.

There is more than one possible explanation for the magnification of the illusion in experiment 1 and weakening of the Müller-Lyer illusion in experiment 2. First, the use of two fingers alone is not sufficient to explain attenuation, since grasping yielded a strong illusion in experiment 1 . The use of two index fingers may have encouraged an exploration strategy in which subjects felt 'beyond' the wings in the wings-in stimuli. 
This is suggested by the finding that the wings-out stimuli were judged as longer in the main experiment reported here (with the use of two index fingers), but the wings-in stimuli were judged as equal to the control stimuli (see table 2). When subjects use a single finger or pair of fingers of one hand to feel patterns, they are likely to stop feeling the lines within the boundary marked by the wings-in endings. Under these circumstances, sensory inhibition could cause subjects to fail to feel the last few millimeters of the horizontal lines. This explanation fits with the first author's introspection, and with comments by blind subjects in earlier research (Heller et al 2002a). In addition, the use of one hand to engage in grasping leads to an awkward posture of the hand and arm when stimuli are at the body midline. This may have discouraged feeling the very tips of the wings-in stimuli. It is suggested that the grasping and measuring strategies of experiment 1 may magnify illusory misperception because they encourage subjects to feel the horizontal lines, in the case of the wings-in stimuli, and not feel the points where the wings intersect with the lines being judged. These exploration strategies probably induce subjects into extending their fingers beyond the end of the horizontal lines for the wings-out stimuli. Failures to judge the precise point where the lines end could prompt underestimation and overestimation of wings-in and wings-out stimuli, respectively. However, the subjects continued to show the illusion for the smaller stimuli in experiment 2, and there was still some overestimation of the wings-out stimuli. These findings are consistent with the idea that the use of two index fingers of two hands yields a reduction in the strength of the illusion for wings-in stimuli by altering exploration strategies.

Furthermore, it is probable that the use of the two index fingers promotes the use of the body as a frame of reference for interpreting line length (see Heller et al 1999; Millar and Al-Attar 2002). Millar and Al-Attar reported that the haptic Müller-Lyer illusion was practically eliminated when subjects were instructed to use body-centered spatial reference cues as they felt Müller-Lyer patterns. Millar and Al-Attar derived their prediction from the Helmholtz explanation of length illusions, namely that they arise from discrepancies in the cues that generally provide accurate perception. Thus, the explanation is intended to be an explanation of accurate and illusory perception. For the Müller-Lyer illusion, there is a discrepancy between the length cues provided by the wing endings and the line shaft. These discrepancies would be reduced, according to Millar and Al-Attar, by experimental manipulations that instruct subjects to relate their length judgments to presumably reliable information about length; that is, their bodies. Millar and Al-Attar reported that instructions to use body-centered reference cues reduced the strength of the illusion from approximately $15.1 \%$ to $2.1 \%$ in haptics, and from $10.1 \%$ to $1.4 \%$ in vision. While subjects in experiment 2 were not instructed to use their bodies as a frame of reference, the use of two fingers of two hands clearly aided veridical performance, in a manner that is consistent with Millar's interpretation. There certainly are ways to try to directly test the body-centered reference frame hypothesis, but this is proposed as a subject for future study.

The present results, and those of Millar and Al-Attar (2002) provide strong support for the idea that perceptual skill may reduce the illusory misperception that one sees in the Müller-Lyer illusion. For example, a sensory inhibition explanation has been offered for underestimation of line length for wings-in stimuli (Heller et al 2002a). It is difficult to feel where lines end when they are embedded within the arrows of the wings-in Müller-Lyer stimuli. Sensory inhibition seemed a plausible explanation. Notably, experiment 2 of this study shows that this putative sensory limitation may be irrelevant with the use of scanning by two index fingers. Note, too, that exploration mode altered judgments of extent for the wings-out, but not the wings-in stimuli in the first two experiments. In addition, Millar and Al-Attar (2002) reported that instructions to use the body as a frame of reference for coding extent had a similar effect in 
practically eliminating the illusion. Therefore, instructions to use egocentric coding allowed participants to improve the accuracy of haptic perception of extent. However, it should be mentioned that Millar's theoretical formulation (1994) is not consistent with the idea of a simplistic dichotomy between sensory and higher-level cognitive processes, since they are both involved in any case where one perceives the environment. Thus, her model assumes integrative (interactive) processes whenever the individual is engaged in perceptual functioning.

\section{Experiment 3: Position and orientation in the haptic illusion}

The object of this experiment was to test whether the haptic Müller-Lyer illusion could be influenced by orientation and position in space. Millar and Al-Attar (2002) found that the Müller-Lyer illusion was not dependent upon the horizontal or vertical orientation, but their stimuli were always flat on the table surface. In the present experiment, the vertical and horizontal orientations were compared, but also the position with respect to gravity was manipulated. Thus, stimuli were vertical or horizontal, but also were placed flat on the table surface or in the frontal plane. The frontal placement was found to radically alter the horizontal - vertical illusion, and yielded an overestimation of horizontals (Heller et al 2003a). Also, earlier research suggests that the frontal placement might reduce perceptual error (Heller 1992). Frontal placement might sensitize subjects to gravitational and body information during exploration, and this might promote egocentric coding. Thus, it was hypothesized that the frontal placement might diminish the Müller-Lyer illusion.

\subsection{Method}

4.1.1 Subjects. There were forty-eight naive undergraduate volunteers, with twelve subjects in each of 4 groups. Half of the subjects in each group were male and half were female.

4.1.2 Stimuli and apparatus. The stimuli and apparatus were similar to those of the first experiment. For frontal placement, the stimuli were held in place on a clipboard that was gravitationally vertical and parallel to the front edge of the table.

4.1.3 Design and procedure. This experiment was a between-within design, with independent groups for position (frontal or flat on the table) and orientation (horizontal or vertical). Repeated measures were taken on type of line ending (wings in, wings out, plain lines, lines with vertical endings), line length (4), and trials (2). Blindfolded subjects felt the tangible stimuli with tracing of the index fingers of their preferred hands, and made size judgments with their left hands. In other respects, the procedure was similar to that of experiment 1.

\subsection{Results and discussion}

The results of experiment 3 are shown in table 3 , and confirm the presence of a robust Müller-Lyer illusion. The illusion was especially strong with the smallest stimuli. The illusion seemed weaker with frontal placement in the horizontal orientation. However, an ANOVA on size estimates revealed a strong illusion $\left(F_{3,132}=37.8, p<0.001\right)$, with overestimation of wings-out patterns, compared to wings-in patterns and other stimuli. The effect of size was highly significant $\left(F_{3,132}=536.9, p<0.001\right)$. It also showed that the effect of position failed to reach significance $(F<1)$, as did the effect of orientation $\left(F_{1,44}=1.43, p>0.23\right)$. However, the interaction between position and orientation was significant $\left(F_{1,44}=5.78, p=0.02\right)$. The simple effect of position was not significant for verticals and horizontals (both $p \mathrm{~s}>0.09$ ), and orientation did not matter for frontal stimuli $(F<1)$. Nonetheless, orientation did significantly alter size estimates when the stimuli were flat on the table surface $(p=0.015)$. Stimuli flat on the table surface were judged as much larger when they were vertical $(M=6.9 \mathrm{~cm})$ than when 
Table 3. Mean size judgments, mean signed error scores (in brackets, below mean size judgments), and illusion strength for the Müller-Lyer and control stimuli as a function of size (with standard deviations in parentheses), position (flat or frontal), and orientation (horizontal or vertical) collapsed across trials for experiment 3 .

\begin{tabular}{llclll}
\hline $\begin{array}{l}\text { Actual stimulus } \\
\text { size } / \mathrm{cm}\end{array}$ & \multicolumn{2}{c}{ Mean size judgment of stimulus $/ \mathrm{cm}$} & & $\begin{array}{l}\text { Illusion } \\
\text { strength } / \%\end{array}$ \\
\cline { 2 - 5 } & wings in & wings out & $\begin{array}{l}\text { vertical } \\
\text { ends }\end{array}$ & $\begin{array}{l}\text { plain } \\
\text { lines }\end{array}$ & overall
\end{tabular}

\section{Flat position/stimuli in horizontal orientation}

$\begin{array}{ccccccc}2.5 & 2.10(0.81) & 3.35(0.78) & 2.66(0.75) & 2.73(0.83) & 2.71 & 50.0 \\ 5.1 & {[-0.40]} & {[0.85]} & {[0.16]} & {[0.23]} & & \\ & 3.93(0.85) & 4.98(1.09) & 4.39(1.52) & 4.63(0.98) & 4.48 & 20.6 \\ 7.6 & {[-1.17]} & {[-0.12]} & {[-0.71]} & {[-0.47]} & & \\ & 5.66(1.27) & 6.75(1.30) & 6.48(1.48) & 6.76(1.68) & 6.41 & 14.3 \\ 10.2 & {[-1.94]} & {[-0.85]} & {[-1.13]} & {[-0.84]} & & \\ & 7.30(1.44) & 8.67(1.81) & 8.83(1.30) & 8.67(2.67) & 8.37 & 13.4 \\ & {[-2.90]} & {[-1.54]} & {[-1.37]} & {[-1.53]} & & \end{array}$

\section{Flat position/stimuli in vertical orientation}

$\begin{array}{ccccccc}2.5 & 2.51(0.94) & 4.28(1.27) & 3.60(0.82) & 3.59(1.34) & 5.19 & 70.8 \\ & {[0.01]} & {[1.78]} & {[1.10]} & {[1.09]} & & \\ 5.1 & 4.85(1.29) & 6.48(1.47) & 5.88(1.67) & 5.98(1.72) & 5.80 & 32.0 \\ & {[-0.25]} & {[1.38]} & {[0.78]} & {[0.88]} & & \\ 7.6 & 6.75(1.53) & 8.47(2.04) & 8.33(2.38) & 8.05(2.28) & 8.0 & 22.6 \\ & {[-0.85]} & {[0.87]} & {[0.73]} & {[0.45]} & & \\ 10.2 & 9.42(1.97) & 10.33(2.37) & 10.73(3.23) & 10.86(3.07) & 10.34 & 8.9 \\ & {[-0.78]} & {[0.13]} & {[0.53]} & {[0.66]} & & \end{array}$

Frontal position/stimuli in horizontal orientation

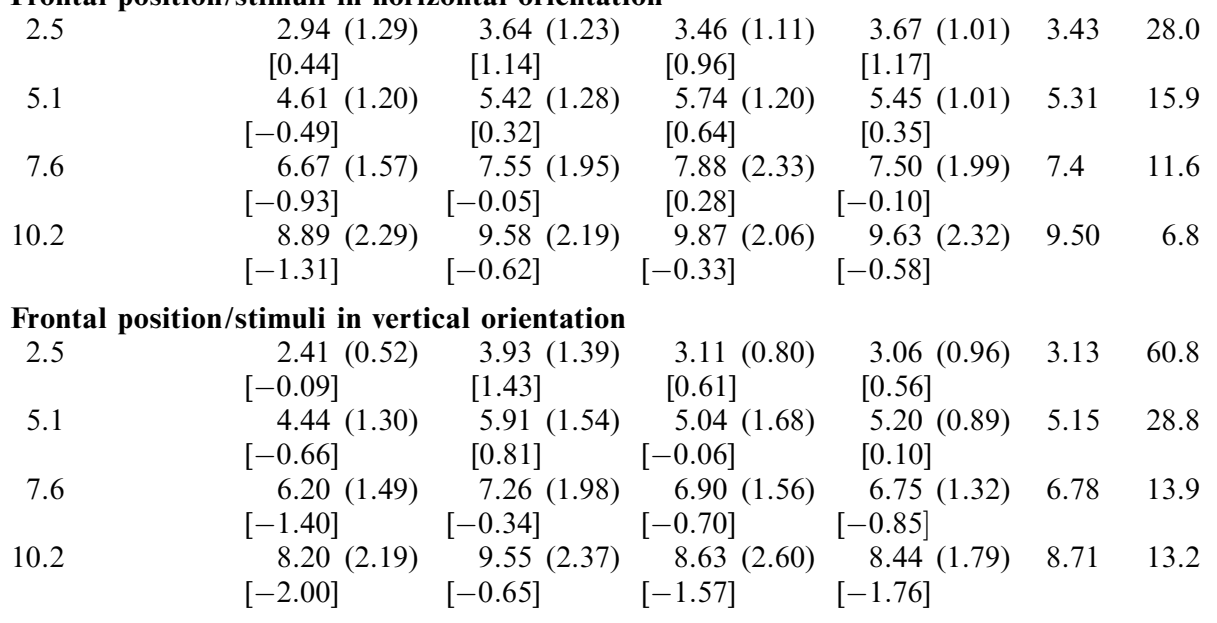

they were horizontal $(M=5.5 \mathrm{~cm})$. Horizontal placement of patterns may explain some of the underestimation of larger stimuli in the first experiment (see tables 1 and 3).

There was also a significant effect of trials, since mean overall size judgments differed between the first trial $(M=6.0 \mathrm{~cm})$ and the second trial $(M=6.32 \mathrm{~cm})$ $\left(F_{1,44}=6.7, p=0.01\right)$. This trials effect represented an increase in the accuracy of length estimates over trials. There was also a significant interaction between position, orientation, and trials $\left(F_{1,44}=9.44, p<0.01\right)$, and between position, orientation, trials, and size $\left(F_{3,132}=2.70, p<0.05\right)$. The three-way interaction derived from the finding that the trials effect was eliminated for frontally oriented verticals. A position by trials interaction failed to reach significance $(p=0.056)$. For flat, vertical stimuli, the 
$10.2 \mathrm{~cm}$ stimuli were judged as smaller on the first trial $(M=9.84 \mathrm{~cm})$ than on the second trial $(M=10.8 \mathrm{~cm})$.

The presence of the Müller-Lyer illusion was not altered by position or orientation, since none of the interactions between type of line ending and position or orientation reached significance (all $p \mathrm{~s}>0.12$ ). These results are consistent with the findings of Millar and Al-Attar (2002).

An ANOVA performed on signed error scores yielded essentially identical results. Mean judged signed error scores for the wings in, wings out, plain lines, and lines with vertical endings were $-0.92,0.28,-0.00$, and -0.04 , respectively. Again, none of the interactions with line endings reached significance (all $p \mathrm{~s}>0.10$ ). For stimuli flat on the table surface, horizontal lines $\left(M_{\mathrm{se}}=-0.86\right)$ were judged as smaller than verticals $\left(M_{\mathrm{se}}=0.53\right)$. However, frontally placed verticals $\left(M_{\mathrm{se}}=-0.41\right)$ were judged as slightly smaller than the horizontals $\left(M_{\mathrm{se}}=0.06\right)$. These results were consistent with reports of overestimation of horizontals compared to verticals when the verticals were vertical with respect to gravity (Heller et al 2003). The stimuli were judged more accurately on the second trial $\left(M_{\mathrm{se}}=-0.03\right)$ than on the first trial $\left(M_{\mathrm{se}}=-0.31 ; p=0.01\right)$.

\section{Experiment 4: Oblique stimuli flat on the table surface}

The purpose of experiment 4 was to further examine the effect of orientation on the haptic illusion. In this experiment, stimuli at oblique orientations were compared with those that were upright (but vertical). Appelle and Countryman (1986) have reported that the haptic oblique effect is influenced by scanning methods. Haptic scanning refers to the manner in which one sequentially examines stimuli with the fingers. It was hypothesized that stimuli might be scanned and judged differently at oblique orientations, and that the magnitude of the Müller-Lyer illusion could be altered by orientation. The stimuli were always flat on the table surface, since experiment 3 showed that orientation of the patterns had minimal effect for the frontal position.

\subsection{Method}

5.1.1 Subjects. There were three groups of naive subjects in experiment 3 ( $N$ per group $=12$; total $N=36$; twenty-one females, fifteen males).

5.1.2 Stimuli and apparatus. The stimuli and apparatus were similar to those of the first two experiments. They were always placed on the table surface, at the subjects' midline. Stimulus orientations included patterns that were vertical, at $-45^{\circ}$ from the vertical, or at $+45^{\circ}$ from the vertical.

5.1.3 Design and procedure. In most respects, the design and procedure were like those of the first two experiments. The design was a between - within ANOVA, with independent groups for stimulus orientation, and repeated measures were taken on line endings, size (4), and trials (2). Subjects traced the stimuli with their right index fingers, and used their left hands to adjust the tangible ruler.

\subsection{Results and discussion}

The results of experiment 4 are shown in table 4 . The main effect of type of line ending was highly significant $\left(F_{3,99}=40.5, p=0.0\right)$ indicating a strong Müller-Lyer illusion with wings-out stimuli $(M=7.0 \mathrm{~cm})$ judged as larger than wings-in patterns $(M=5.6 \mathrm{~cm})$. However, the main effect of orientation failed to reach significance $(F<1)$, as did the interaction between orientation and type of line ending $(F<1)$. The effect of size was highly significant $\left(F_{3,99}=392.7, p<0.001\right)$. There was a significant size by trials interaction $\left(F_{3,99}=3.9, p<0.02\right)$, but the simple effect of size was significant for both trials $(p=0.0)$. The interaction between line orientation, line ending, and size failed to reach significance $(p=0.098)$, as did the interaction between orientation, line ending, and trials $(p=0.094)$. 
Table 4. Mean size judgments, mean signed error scores (in brackets, beneath mean size judgments), and illusion strength for Müller-Lyer and control stimuli as a function of size (with standard deviations in parentheses) and orientation $\left(+45^{\circ},-45^{\circ}\right.$, and vertical) collapsed across trials for experiment 4 . All stimuli in experiment 4 were flat on the table surface.

\begin{tabular}{|c|c|c|c|c|c|}
\hline \multirow{2}{*}{$\begin{array}{l}\text { Actual stimulus } \\
\text { size } / \mathrm{cm}\end{array}$} & \multicolumn{4}{|c|}{ Mean size judgment of stimulus $/ \mathrm{cm}$} & \multirow{2}{*}{$\begin{array}{l}\text { Illusion } \\
\text { strength/\% }\end{array}$} \\
\hline & wings in & wings out & $\begin{array}{l}\text { plain } \\
\text { lines }\end{array}$ & $\begin{array}{l}\text { vertical } \\
\text { ends }\end{array}$ & \\
\hline \multicolumn{6}{|l|}{$+45^{\circ}$ orientation } \\
\hline 2.5 & $\begin{array}{l}1.94(0.34) \\
{[-0.56]}\end{array}$ & $\begin{array}{l}3.59(1.15) \\
{[1.09]}\end{array}$ & $\begin{array}{l}2.96(0.48) \\
{[0.46]}\end{array}$ & $\begin{array}{l}2.83(0.51) \\
{[0.33]}\end{array}$ & 66.0 \\
\hline 5.1 & $\begin{array}{l}4.80(1.15) \\
{[-0.35]}\end{array}$ & $\begin{array}{l}6.17(1.12) \\
{[1.07]}\end{array}$ & $\begin{array}{l}5.57(1.19) \\
{[0.47]}\end{array}$ & $\begin{array}{l}5.26(1.53) \\
{[0.16]}\end{array}$ & 26.9 \\
\hline 7.6 & $\begin{array}{l}7.13(1.68) \\
{[-0.47]}\end{array}$ & $\begin{array}{l}8.15(1.45) \\
{[0.55]}\end{array}$ & $\begin{array}{l}7.86(1.12) \\
{[0.26]}\end{array}$ & $\begin{array}{l}7.53(1.92) \\
{[-0.08]}\end{array}$ & 13.4 \\
\hline 10.2 & $\begin{array}{l}9.50(2.04) \\
{[-0.70]}\end{array}$ & $\begin{array}{c}10.0 \\
{[-0.18]}\end{array}$ & $\begin{array}{l}9.54(1.47) \\
{[-0.66]}\end{array}$ & $\begin{array}{l}9.93(2.39) \\
{[-0.27]}\end{array}$ & 4.9 \\
\hline \multicolumn{6}{|l|}{$-45^{\circ}$ orientation } \\
\hline 2.5 & $\begin{array}{l}1.97(0.60) \\
{[-0.53]}\end{array}$ & $\begin{array}{l}3.21(0.75) \\
{[0.71]}\end{array}$ & $\begin{array}{l}2.80(0.82) \\
{[0.30]}\end{array}$ & $\begin{array}{l}2.75(0.78) \\
{[0.25]}\end{array}$ & 49.6 \\
\hline 5.1 & $\begin{array}{l}3.91(0.85) \\
{[-0.19]}\end{array}$ & $\begin{array}{l}5.44(1.55) \\
{[0.34]}\end{array}$ & $\begin{array}{l}5.13(1.55) \\
{[0.03]}\end{array}$ & $\begin{array}{l}4.87(1.30) \\
{[-0.23]}\end{array}$ & 30.0 \\
\hline 7.6 & $\begin{array}{l}5.90(1.68) \\
{[-1.70]}\end{array}$ & $\begin{array}{l}7.63(2.69) \\
{[0.03]}\end{array}$ & $\begin{array}{l}7.33(2.39) \\
{[-0.27]}\end{array}$ & $\begin{array}{l}7.15(2.03) \\
{[-0.45]}\end{array}$ & 22.8 \\
\hline 10.2 & $\begin{array}{l}8.35(2.35) \\
{[-1.85]}\end{array}$ & $\begin{array}{l}10.08(2.78) \\
{[-0.12]}\end{array}$ & $\begin{array}{l}9.31(2.87) \\
{[-0.89]}\end{array}$ & $\begin{array}{l}8.67(2.72) \\
{[-1.53]}\end{array}$ & 17.0 \\
\hline \multicolumn{6}{|c|}{ Vertical orientation } \\
\hline 2.5 & $\begin{array}{l}2.06(0.35) \\
{[-0.44]}\end{array}$ & $\begin{array}{l}3.76(0.78) \\
{[1.26]}\end{array}$ & $\begin{array}{l}3.05(0.63) \\
{[0.55]}\end{array}$ & $\begin{array}{l}2.99(0.56) \\
{[0.49]}\end{array}$ & 68.0 \\
\hline 5.1 & $\begin{array}{l}4.28(0.94) \\
{[-0.82]}\end{array}$ & $\begin{array}{l}6.23(1.52) \\
{[1.13]}\end{array}$ & $\begin{array}{l}5.44(1.38) \\
{[0.34]}\end{array}$ & $\begin{array}{l}5.31(1.17) \\
{[0.21]}\end{array}$ & 38.2 \\
\hline 7.6 & $\begin{array}{l}7.24(1.86) \\
{[-0.36]}\end{array}$ & $\begin{array}{l}8.85(2.24) \\
{[1.25]}\end{array}$ & $\begin{array}{l}8.15(2.38) \\
{[0.55]}\end{array}$ & $\begin{array}{l}7.66(1.72) \\
{[0.06]}\end{array}$ & 21.2 \\
\hline 10.2 & $\begin{array}{l}9.68(2.57) \\
{[-0.53]}\end{array}$ & $\begin{array}{l}10.72(2.51) \\
{[0.52]}\end{array}$ & $\begin{array}{l}10.35(2.84) \\
{[0.15]}\end{array}$ & $\begin{array}{l}9.82(2.51) \\
{[-0.038]}\end{array}$ & 10.2 \\
\hline
\end{tabular}

The experiment did yield an interesting interaction between orientation, type of line ending, size, and trials $\left(F_{18,297}=1.8, p=0.025\right)$. This interaction derived from a weaker $(4.9 \%)$ illusion for the largest stimuli at $+45^{\circ}$. The illusion was stronger $(17.0 \%)$ for the largest stimuli at $-45^{\circ}$ (see table 4). Note that scanning methods probably differed for the stimuli at these two orientations. Stimuli at $+45^{\circ}$ could be felt by pivoting the arm at the elbow, while scanning stimuli at the other oblique $\left(-45^{\circ}\right)$ probably induced motion of the entire arm. Whole-arm motion has been shown to magnify illusory misperception in the horizontal-vertical illusion (Heller et al 1997). The haptic horizontal-vertical illusion disappeared when motion of the arm was prevented and subjects were restricted to finger exploration.

An ANOVA on signed error scores yielded identical results. Mean signed error scores for the wings in, wings out, lines with vertical endings, and plain lines, were -0.79 , $0.64,-0.12$, and 0.11 , respectively. A Newman-Keuls test showed that the wings-in and wings-out means were significantly different from all of the other means, and from each other $(p<0.01)$. The size by trials interaction derived from a tendency to underestimate the two larger stimuli on the second trial, but this was not found for the smaller sizes. The interaction between orientation, line ending, and size failed to reach significance $(p=0.098)$, as did the interaction between orientation, line ending, and trials $(p=0.09)$. 


\section{Experiment 5: Lack of an effect of line thickness in haptics}

It is reasonable to expect that the illusion would be diminished if it were easier for subjects to discriminate the line shaft from the wing endings. To test this, Müller-Lyer stimuli were produced with progressively thicker shafts, while the line endings remained the same length and thickness as in the other experiments reported here. The increased line thickness was expected to aid the discriminability of the lines from the thinner wing endings. It was expected that increasing line shaft thickness should yield reduced illusory misperception, with the maximal effect for the thickest lines.

\subsection{Method}

6.1.1 Subjects. There were thirty-six subjects, with twelve participants (six male, six female) in each of the 3 groups. All subjects were naive.

6.1.2 Stimuli and apparatus. The stimuli were similar to those of the earlier experiments, with the exception of the thickness of the shafts (see figure 3). One set of standard stimuli used a line thickness of $1 \mathrm{~mm}$, as in experiments $1-4$. The other stimuli had line endings that were $1 \mathrm{~mm}$ thick, but they had shafts that were thicker $(1.5 \mathrm{~mm}$ and $2.5 \mathrm{~mm}$ ). In all stimulus conditions, the line endings were $1 \mathrm{~mm}$ thick.

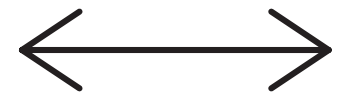

(a)

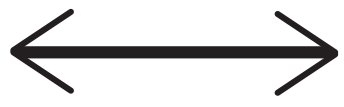

(b)

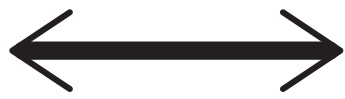

(c)
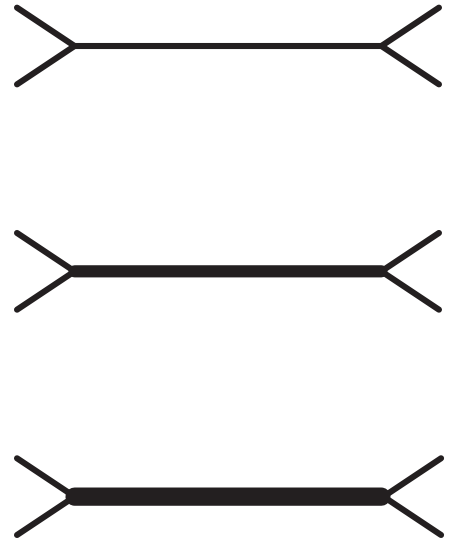

Figure 3. The Müller-Lyer stimuli with line shaft thickness of (a) $1 \mathrm{~mm}$, (b) $1.5 \mathrm{~mm}$, and (c) $2.5 \mathrm{~mm}$. The endings were always $1 \mathrm{~mm}$ thick.

6.1.3 Design and procedure. The experiment was a between - within design, with independent groups for shaft thickness $(1,1.5$, and $2.5 \mathrm{~mm})$, with repeated measures taken on line ending (wings in, wings out, plain lines, vertical ends), size $(2.5,5.1,7.6$, and $10.2 \mathrm{~cm}$ ), and trials (2). Blindfolded subjects used their right index fingers to feel the stimuli and made size estimates with their other hands, as in the earlier experiments reported here. In other respects, the method was like that of the other experiments.

As in experiment 1, a powerful haptic Müller-Lyer illusion was obtained (see table 5). The participants underestimated wings-in stimuli as compared with the wings-out patterns. Mean overall size judgments were $6.54 \mathrm{~cm}, 6.22 \mathrm{~cm}$, and $5.97 \mathrm{~cm}$, for the $1 \mathrm{~mm}$, $1.5 \mathrm{~mm}$, and $2.5 \mathrm{~mm}$ shaft thickness conditions, respectively. The main effect of shaft thickness failed to reach significance $(F<1)$, but the effect of line ending was highly significant $\left(F_{3,99}=30.4, p<0.001\right)$, as was the effect of size $\left(F_{3,99}=475.8, p<0.001\right)$. However, the interaction between line shaft thickness and line ending failed to reach significance $\left(F_{6,99}=2.0, p=0.067\right)$. The illusion was not weaker with the thicker line shafts; rather, it seemed slightly stronger. In addition, there was a non-significant interaction between line thickness and size $\left(F_{6,99}=2.1, p=0.061\right)$. There was a slight tendency toward underestimation of the largest stimuli with the thickest line shafts. 
Table 5. Mean size judgments, mean signed error scores (in brackets, beneath mean size judgments), and illusion strength as a function of figure, size (standard deviations in parentheses), and line thickness $(1.0,1.5$, and $2.5 \mathrm{~mm})$ in experiment 5 .

\begin{tabular}{|c|c|c|c|c|c|}
\hline \multirow{2}{*}{$\begin{array}{l}\text { Actual stimulus } \\
\text { size } / \mathrm{cm}\end{array}$} & \multicolumn{4}{|c|}{ Mean size judgment of stimulus/cm } & \multirow{2}{*}{$\begin{array}{l}\text { Illusion } \\
\text { strength } / \%\end{array}$} \\
\hline & wings in & wings out & $\begin{array}{l}\text { vertical } \\
\text { ends }\end{array}$ & $\begin{array}{l}\text { plain } \\
\text { lines }\end{array}$ & \\
\hline
\end{tabular}

\section{$1.0 \mathrm{~mm}$ line thickness}

$\begin{array}{cc}2.5 & 2.43(0.51) \\ & {[-0.07]} \\ 5.1 & 4.40(1.15) \\ & {[-0.70]} \\ 7.6 & 6.82(1.67) \\ & {[-0.78]} \\ 10.2 & 9.75(1.74) \\ & {[-0.45]}\end{array}$

$\begin{array}{lc}3.38(0.83) & 3.13(0.52) \\ {[0.88]} & {[0.63]} \\ 5.56(1.30) & 5.33(0.84) \\ {[0.46]} & {[0.23]} \\ 8.11(1.79) & 7.67(1.25) \\ {[0.51]} & {[0.07]} \\ 10.26(1.95) & 9.72(1.48) \\ {[0.06]} & {[-0.48]}\end{array}$

$\begin{array}{ll}3.16(0.73) & 38.0 \\ {[0.66]} & \\ 5.85(1.62) & 22.7 \\ {[0.75]} & \\ 8.13(1.81) & 17.0 \\ {[0.53]} & \\ 10.88(2.22) & 5.0 \\ {[0.68]} & \end{array}$

\section{$1.5 \mathrm{~mm}$ line thickness}

$\begin{array}{cc}2.5 & 2.73(0.71) \\ & {[0.23]} \\ 5.1 & 4.46(0.80) \\ & {[-0.64]} \\ 7.6 & 7.00(1.57) \\ & {[-0.60]} \\ 10.2 & 8.88(1.90) \\ & {[-1.32]}\end{array}$

$\begin{array}{lc}3.73(0.70) & 2.95(0.63) \\ {[1.23]} & {[0.45]} \\ 5.69(1.09) & 5.08(0.84) \\ {[0.59]} & {[-0.02]} \\ 7.92(1.59) & 7.15(1.48) \\ {[0.32]} & {[-0.74]} \\ 9.91(2.34) & 9.46(2.66) \\ -0.29] & {[-0.74]}\end{array}$

\begin{tabular}{|c|c|}
\hline \multicolumn{2}{|l|}{$3.05(0.73)$} \\
\hline \multicolumn{2}{|l|}{$[0.55]$} \\
\hline \multicolumn{2}{|l|}{$5.11(1.14)$} \\
\hline \multicolumn{2}{|l|}{$[0.01]$} \\
\hline \multicolumn{2}{|l|}{$7.39(1.60)$} \\
\hline \multicolumn{2}{|l|}{$[-0.21]$} \\
\hline \multirow{2}{*}{$\begin{array}{l}9.01(2.48) \\
-1.19]\end{array}$} & \\
\hline & \\
\hline
\end{tabular}

\section{$2.5 \mathrm{~mm}$ line thickness}

$\begin{array}{cccccc}2.5 & 2.25(0.54) & 3.85(1.31) & 2.98(0.56) & 2.95(0.79) & 64.0 \\ 5.1 & {[-0.25]} & {[1.35]} & {[0.48]} & {[0.45]} & \\ & 4.40(1.15) & 5.74(1.47) & 4.78(0.89) & 5.30(1.45) & 26.3 \\ 7.6 & {[-0.58]} & {[0.64]} & {[-0.32]} & {[0.20]} & \\ & 6.40(1.62) & 7.62(2.04) & 6.77(1.56) & 6.22(1.72) & 16.1 \\ 10.2 & {[-1.20]} & {[0.02]} & {[-0.75]} & {[-0.22]} & \\ & 7.93(1.90) & 9.40(2.19) & 8.70(1.95) & 8.94(1.59) & 14.4 \\ & {[-2.27]} & {[-0.80]} & {[-1.50]} & {[-1.26]} & \end{array}$

The main effect of trials was non-significant $(F<1)$, but there was a significant interaction between line thickness, size, and trials $\left(F_{6,99}=2.5, p<0.03\right)$. Stimuli were judged as smaller for the medium line thickness, and the largest patterns on the second trial. This may have been a spurious finding, since a very small proportion of the total variance can be attributed to this interaction $(<1 \%$ of the variation due to the main effect of thickness). None of the other interactions with line thickness approached significance (all $p \mathrm{~s}>0.11$ ).

The results of an ANOVA on signed error scores were identical. Mean signed error scores for the wings in, wings out, plain lines, and lines with vertical ends were -0.72 , $0.41,-0.23$, and 0.08 , respectively. The main effect of size was significant $\left(F_{3,99}=20.02\right.$, $p<0.001)$. In increasing size order, mean signed error scores for the stimuli were $0.55,0.05,-0.25$, and -0.80 . The interaction between line shaft thickness and line ending failed to reach significance $(p=0.09)$, as did the interaction between line ending, thickness, and size $(p=0.10)$.

The present results are consistent with earlier reports indicating that the haptic Müller-Lyer illusion is robust, and difficult to completely eliminate. Millar and Al-Attar (2002) increased the distinctiveness of the wings by making them textured and altering their length. The effect of altering the distinctiveness of the wings mattered for vision. However, in touch, the effect of small textured wings was only significant in 
conditions where they were close enough to the line shaft to be scanned in close proximity. These effects were much smaller than the effect of instructions to use body-centered reference cues.

The results of experiment 5 are also not inconsistent with earlier reports (Heller et al 2002a) of a large effect of the angle of the wings, since alteration of shaft thickness in experiment 5 had no effect on the angle of the wings. More acute angles maximized the illusion in Heller et al's report, and more obtuse angles reduced the magnitude of the illusion.

\section{Experiment 6: Small effect of wing length on the haptic illusion}

Millar and Al-Attar (2002) recently reported that the length of the wings influenced the strength of the Müller-Lyer illusion. Note that they manipulated the texture of the line endings along with the length of the endings. Both texture and length could have contributed to the modification of the strength of the illusion, with shorter textured lines leading to a slightly reduced illusion. While Heller et al (2002a) found that more acute wing angles yielded stronger haptic illusory distortion, in that study they did not control for the increase in the global size of the stimuli with more acute wing angles. In experiment 6 , the length of the wings was manipulated on the assumption that shorter wing endings would produce a weaker haptic illusion, if subjects respond to the global size of the patterns (DeLucia 1993).

\subsection{Method}

7.1.1 Subjects. Twelve blindfolded naive subjects (six male, six female) volunteered for this experiment.

7.1.2 Stimuli and apparatus. The stimuli were limited to the wings-in and wings-out patterns on swell-paper. The $2.54 \mathrm{~cm}$ patterns were not used, since the wings-in endings would have overlapped. The wing lengths were $0.7 \mathrm{~cm}, 1.4 \mathrm{~cm}$, and $2.1 \mathrm{~cm}$ (see figure 4). Note that the $1.4 \mathrm{~cm}$ length was identical to that used in experiments $1-5$, and comparable to the shorter line endings used by Millar and Al-Attar (2002). Control stimuli were not included. As in the earlier experiments, a tangible ruler was used for size judgments.

7.1.3 Design and procedure. In this experiment, the design was entirely within-groups, with repeated measures on the length of the wing endings $(0.7,1.4$, and $2.1 \mathrm{~cm})$, wing direction (in, out), size $(5.1,7.6,10.2 \mathrm{~cm})$, and trials (2). The order of presentation of the

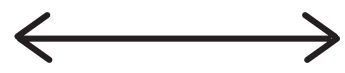

(a)

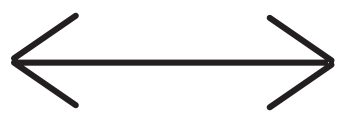

(b)

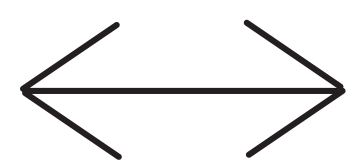

(c)
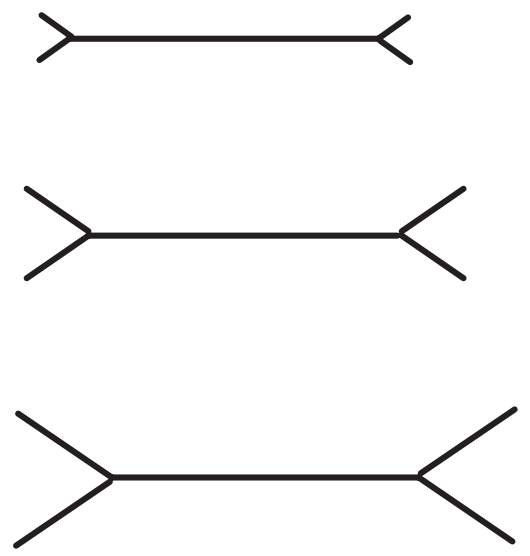

Figure 4. The Müller-Lyer stimuli with wing endings of (a) $0.7 \mathrm{~cm}$, (b) $1.4 \mathrm{~cm}$, and (c) $2.1 \mathrm{~cm}$. 
wing-length condition was randomized. In other respects, the procedure was similar to that of experiments $1-5$.

Experiment 6 yielded a Müller-Lyer illusion, since wings-out stimuli $(M=7.1 \mathrm{~cm})$ were judged as significantly longer than wings-in patterns $(M=6.4 \mathrm{~cm})\left(F_{1,9}=55.9\right.$, $p<0.001$ ) (see table 6 ). The effect of line size was significant $\left(F_{2,18}=79.0, p<0.001\right)$, but the main effect of wing length was non-significant $(F<1)$. The stimuli were judged as equivalent in length, despite differences in the lengths of the wings. Mean judged sizes were $6.74 \mathrm{~cm}, 6.66 \mathrm{~cm}$, and $6.84 \mathrm{~cm}$, for stimuli with $0.7 \mathrm{~cm}, 1.4 \mathrm{~cm}$, and $2.1 \mathrm{~cm}$ long wings, respectively. The main effect of trials failed to reach significance $(F<1)$.

Table 6. Mean size judgments, mean signed error scores (in brackets, beneath mean size judgments), and illusion strength as a function of figure, size (with standard deviations in parentheses), and wing length (data collapsed across trials).

\begin{tabular}{|c|c|c|c|c|}
\hline \multirow{2}{*}{$\begin{array}{l}\text { Actual stimulus } \\
\text { size } / \mathrm{cm}\end{array}$} & \multicolumn{3}{|c|}{ Mean size judgment of stimulus/cm } & \multirow{2}{*}{$\begin{array}{l}\text { Illusion } \\
\text { strength } / \%\end{array}$} \\
\hline & wings in & wings out & overall & \\
\hline \multicolumn{5}{|c|}{$7 \mathrm{~mm}$ wing length } \\
\hline 5.1 & $\begin{array}{l}4.92(1.38) \\
{[-0.19]}\end{array}$ & $\begin{array}{l}5.45(1.55) \\
{[0.35]}\end{array}$ & 5.18 & 10.4 \\
\hline 7.6 & $\begin{array}{l}6.40(1.95) \\
{[-1.20]}\end{array}$ & $\begin{array}{l}7.04(1.55) \\
{[-0.56]}\end{array}$ & 6.72 & 8.4 \\
\hline 10.2 & $\begin{array}{l}8.07(1.99) \\
{[-2.13]}\end{array}$ & $\begin{array}{l}8.59(1.65) \\
{[-1.62]}\end{array}$ & 8.33 & 5.1 \\
\hline \multicolumn{5}{|c|}{$14 \mathrm{~mm}$ wing length } \\
\hline 5.1 & $\begin{array}{l}4.49(1.11) \\
{[-0.61]}\end{array}$ & $\begin{array}{l}5.41(1.66) \\
{[0.31]}\end{array}$ & 4.95 & 18.0 \\
\hline 7.6 & $\begin{array}{l}6.42(1.63) \\
{[-1.19]}\end{array}$ & $\begin{array}{l}6.79(1.67) \\
{[-0.82]}\end{array}$ & 6.61 & 4.9 \\
\hline 10.2 & $\begin{array}{l}8.22(1.83) \\
{[-1.99]}\end{array}$ & $\begin{array}{l}8.67(2.17) \\
{[-1.53]}\end{array}$ & 8.44 & 4.4 \\
\hline \multicolumn{5}{|c|}{$21 \mathrm{~mm}$ wing length } \\
\hline 5.1 & $\begin{array}{l}4.64(1.38) \\
{[-0.46]}\end{array}$ & $\begin{aligned} & 6.45(1.97) \\
& {[-0.34] }\end{aligned}$ & 5.55 & 35.5 \\
\hline 7.6 & $\begin{array}{l}6.43(1.51) \\
{[-1.17]}\end{array}$ & $\begin{array}{l}7.28(1.81) \\
{[0.30]}\end{array}$ & 6.86 & 11.2 \\
\hline 10.2 & $\begin{array}{l}7.91(2.31) \\
{[-1.83]}\end{array}$ & $\begin{array}{l}8.34(2.51) \\
{[-1.87]}\end{array}$ & 8.13 & 4.2 \\
\hline
\end{tabular}

A significant interaction was found between wing direction and the size of the lines $\left(F_{2,18}=4.14, p<0.05\right)$. There was a much stronger illusion for the smaller than for the larger stimuli. There was a non-significant interaction between wing length and wing direction, $(F<1)$. This suggested that the presence of the illusion might not be influenced by wing length in haptics; however, a somewhat different story emerged from subsequent analyses. The interaction between wing length and size failed to reach significance $\left(F_{4,36}=2.6, p=0.055\right)$. All of the other main effects and interaction effects failed to reach significance (all $p \mathrm{~s}>0.10$ ).

A second ANOVA on signed error scores yielded similar results. Overall, wings-in stimuli $\left(M_{\mathrm{se}}=-1.2\right)$ were judged as smaller than wings-out patterns $\left(M_{\mathrm{se}}=-0.64\right)$. The main effect of wing length was non-significant $(F<1)$, as was the interaction between wing length and wing direction $(F<1)$. However, there was a significant interaction between length of line ending, wing direction, and line size $\left(F_{4,36}=3.69\right.$, $p=0.013)$. The interaction was explained by a lack of any difference in mean signed error scores between wings-in $\left(M_{\mathrm{se}}=-1.83\right)$ and wings-out $\left(M_{\mathrm{se}}=-1.87\right)$ stimuli for 
the largest, $10.2 \mathrm{~cm}$ patterns. There was little evidence of any effect of wing length for the $10.2 \mathrm{~cm}$ stimuli as wing length increased from $0.7 \mathrm{~cm}(\mathrm{PI}=5.1 \%)$ to $2.1 \mathrm{~cm}$ $(\mathrm{PI}=4.2 \%)$. In terms of percentage illusion-strength scores, the effect of wing length appeared greatest for the smallest, $5.1 \mathrm{~cm}$ stimuli, and for these stimuli the illusion was much stronger for the longest wings $(\mathrm{PI}=35.5 \%)$ as compared with the shortest wings $(\mathrm{PI}=0.4 \%)$. In addition, for the longest wing endings and the $7.6 \mathrm{~cm}$ lines, the illusory difference was magnified between wings-in $(M=-1.17)$ and the wings-out $(M=0.30)$ stimuli. The Müller-Lyer illusion appeared weakest with larger patterns, where the wing endings comprise a smaller portion of the entire configuration. Consistent with this explanation was the significant interaction between wing direction, size, and trials $(p<0.05)$. The largest wings-out stimuli $\left(M_{\mathrm{se}}=-2.1\right)$ were judged as similar in size on the second trial to the largest wings-in stimuli $\left(M_{\mathrm{se}}=-2.3\right)$. There was also a four-way interaction between wing length, wing direction, size, and trials. The interaction took the form of an increased underestimation of the largest wings-out patterns on the second trial $\left(M_{\mathrm{se}}=-2.36\right)$ compared with the first trial $\left(M_{\mathrm{se}}=-1.37\right)\left(F_{4,36}=4.2, p<0.01\right)$. The interaction between wing length, wing direction, and trials failed to reach significance $(p=0.09)$.

The data on wing length suggest that the results of some earlier studies on the haptic Müller-Lyer illusion may not be explainable only in terms of this variable. Millar and Al-Attar (2002) found a weaker illusion for smaller, textured lines. Heller et al (2002a) reported an increase in the strength of the illusion as the angle of the wings decreased. In that study, reduced angles occurred along with increases in the overall length of the wings-out stimuli. Note that it is possible that wing length might matter in many cases, even though the effect did not show up in the present size-judgment data, and was only obvious when considering percentage illusion-strength scores for the smallest, $5.1 \mathrm{~cm}$ stimuli. One reviewer pointed out, for example, that the manipulation of wing length may not adequately test the global-pattern-size hypothesis, since other factors are also involved in global size. These variables include the area enclosed by the wings and the centroid of the area (see DeLucia et al 1994).

\section{Experiment 7: The visual illusion}

Subjects in experiment 7 viewed line drawings of the Müller-Lyer stimuli of the earlier experiments. The purpose of the experiment was to provide a visual baseline for interpreting the data from experiments $1-6$, and to examine the possible effect of the hand that was used to adjust the ruler for size judgments. Half of the subjects used their left hands for haptic size estimates, and half used their right hands. It was not clear if the hand used for size estimates mattered, but, if it did, one might expect stronger size distortion with the use of the right hand. Illusory distortion should be greater when information is projected to the left brain (Heller et al 1997).

\subsection{Method}

8.1.1 Subjects. There were twenty-four right-handed subjects; half of the subjects in each group were male and half were female. All of the subjects were naive and had not participated in any of the earlier experiments in this study.

8.1.2 Stimuli and apparatus. The stimuli were visual representations of the Müller-Lyer patterns of experiment 1 , with wings in, wings out, lines with vertical ends, and plain lines. The 2.5, 5.1, 7.6, and $10.2 \mathrm{~cm}$ stimuli were presented at the body midline. Sight of the haptic ruler was obscured with a vertical Masonite panel that had a large rectangular opening at the base. The opening was covered with an opaque cloth. This allowed subjects to manipulate the haptic ruler on the other side of the panel, while simultaneously viewing the Müller-Lyer stimuli. 
8.1.3 Design and procedure. The experiment was a mixed design, with independent groups for the hand used to adjust the tangible ruler, and repeated measures on figure (wings in, wings out, plain lines, lines with vertical ends), size (4), and trials (2). The procedure was similar to that of the first experiment, with the exception that the mode of presentation of the stimuli was purely visual. Independent groups of subjects made size judgments with their left or right hands.

\subsection{Results and discussion}

The results, shown in table 7, indicate the presence of a Müller-Lyer illusion. The wings-out stimuli $(M=5.97 \mathrm{~cm})$ were judged as larger than wings-in patterns $(M=5.31 \mathrm{~cm})$; plain lines $(M=5.54 \mathrm{~cm})$ and lines with vertical endings $(M=5.53 \mathrm{~cm})$ were judged as intermediate in size. Mean size estimates were very similar for the left hand $(M=5.52 \mathrm{~cm})$ and the right hand $(M=5.65 \mathrm{~cm})$. An ANOVA on mean size estimates showed that the effect of hand was non-significant $(F<1)$, but the effect of type of line ending was highly significant $\left(F_{3,66}=25.7, p<0.001\right)$. The Müller-Lyer illusion was robust and was not influenced by the hand used to make size estimates. While the effect of stimulus size was highly significant $\left(F_{3,66}=437.56, p<0.001\right)$, none of the other main effects or interaction effects approached significance (all $p \mathrm{~s}>0.18$ ). The effect of trials failed to reach significance $(F<1)$.

Table 7. Mean size judgments, mean signed error scores (in brackets, beneath mean size judgments), and illusion strength for the Müller-Lyer illusion as a function of hand, figure, and size (with standard deviations in parentheses) for vision in experiment 7 (data collapsed across trials).

\begin{tabular}{|c|c|c|c|c|c|c|}
\hline \multirow{2}{*}{$\begin{array}{l}\text { Actual stimulus } \\
\text { size } / \mathrm{cm}\end{array}$} & \multicolumn{5}{|c|}{ Mean size judgment of stimulus/cm } & \multirow{2}{*}{$\begin{array}{l}\text { Illusion } \\
\text { strength } / \%\end{array}$} \\
\hline & wings in & wings out & $\begin{array}{l}\text { vertical } \\
\text { ends }\end{array}$ & $\begin{array}{l}\text { plain } \\
\text { lines }\end{array}$ & overall & \\
\hline \multicolumn{7}{|c|}{ Left hand adjusts haptic ruler } \\
\hline 2.5 & $\begin{array}{l}2.68(0.51) \\
{[0.18]}\end{array}$ & $\begin{array}{l}3.28(0.80) \\
{[0.78]}\end{array}$ & $\begin{array}{l}2.82(0.46) \\
{[0.32]}\end{array}$ & $\begin{array}{l}2.89(0.54) \\
{[0.39]}\end{array}$ & 2.92 & 24.0 \\
\hline 5.1 & $\begin{array}{l}4.27(0.79) \\
{[-0.83]}\end{array}$ & $\begin{array}{l}5.01(0.91) \\
{[-0.09]}\end{array}$ & $\begin{array}{l}4.57(0.62) \\
{[-0.53]}\end{array}$ & $\begin{array}{l}4.70(0.95) \\
{[-0.40]}\end{array}$ & 4.64 & 14.5 \\
\hline 7.6 & $\begin{array}{l}6.01(1.33) \\
{[-1.59]}\end{array}$ & $\begin{array}{r}6.67(1.24) \\
{[-0.93]}\end{array}$ & $\begin{array}{l}6.24(1.12) \\
{[-1.36]}\end{array}$ & $\begin{array}{l}6.44(1.48) \\
{[-1.16]}\end{array}$ & 6.34 & 8.7 \\
\hline 10.2 & $\begin{array}{l}8.07(1.69) \\
{[-2.13]}\end{array}$ & $\begin{array}{l}8.42(1.51) \\
{[-1.78]}\end{array}$ & $\begin{array}{l}8.03(1.50) \\
{[-2.17]}\end{array}$ & $\begin{array}{l}8.23(1.69) \\
{[-1.97]}\end{array}$ & 8.19 & 3.4 \\
\hline \multicolumn{7}{|c|}{ Right hand adjusts haptic ruler } \\
\hline 2.5 & $\begin{array}{l}2.81(0.67) \\
{[0.31]}\end{array}$ & $\begin{array}{l}3.23(0.84) \\
{[0.73]}\end{array}$ & $\begin{array}{l}2.76(0.47) \\
{[0.26]}\end{array}$ & $\begin{array}{l}2.61(0.46) \\
{[0.11]}\end{array}$ & 2.85 & 16.8 \\
\hline 5.1 & $\begin{array}{l}4.44(0.69) \\
{[-0.66]}\end{array}$ & $\begin{array}{l}5.18(0.97) \\
{[0.08]}\end{array}$ & $\begin{array}{l}4.70(0.74) \\
{[-0.40]}\end{array}$ & $\begin{array}{l}4.77(0.91) \\
{[-0.33]}\end{array}$ & 4.77 & 14.5 \\
\hline 7.6 & $\begin{array}{l}6.08(1.02) \\
{[-1.52]}\end{array}$ & $\begin{array}{l}7.07(1.24) \\
{[-0.53]}\end{array}$ & $\begin{array}{l}6.60(1.24) \\
{[-1.00]}\end{array}$ & $\begin{array}{l}6.38(1.31) \\
{[-1.22]}\end{array}$ & 6.53 & 13.0 \\
\hline 10.2 & $\begin{array}{l}8.17(1.41) \\
{[-2.03]}\end{array}$ & $\begin{array}{l}8.88(1.75) \\
{[-1.33]}\end{array}$ & $\begin{array}{l}8.49(1.39) \\
{[-1.71]}\end{array}$ & $\begin{array}{l}8.26(1.42) \\
{[-1.94]}\end{array}$ & 8.45 & 7.0 \\
\hline
\end{tabular}

An ANOVA on signed error scores produced results that were identical to the main analysis reported here. Mean signed error scores for the wing in, wings out, plain lines, and lines with vertical ends were $-1.04,-0.38,-0.81$, and -0.82 , respectively. Mean signed error scores for the right hand $\left(M_{\mathrm{se}}=-0.7\right)$ were similar to those for the left hand $\left(M_{\mathrm{se}}=-0.83\right)$. In increasing size order, mean signed error scores for the stimuli were $0.39,-0.40,-1.16$, and -1.88 .

One reviewer suggested that it might prove interesting to determine the consequences of bimodal exposure to the stimuli. The reasoning was that a somewhat different pattern of responses to the illusory stimuli was shown by the use of two fingers in 
haptics in experiment 2, and with vision in experiment 7. The idea was to compare vision and bimodal input to determine possible dominance relations. However, it would not be completely appropriate to compare the touch condition with the present data, since subjects using touch alone varied in their response strategies. Some subjects felt the lines and the ruler at the same time, but some did not. An examination of the tables indicates that in terms of percentage illusion-strength scores, the illusion seemed slightly weaker for the use of two index fingers of two hands than with vision. A bimodal condition was run, with twelve right-handed subjects both viewing and feeling the Müller-Lyer stimuli. The stimuli were placed in front of the panel, as in experiment 7, and subjects were allowed to feel the Müller-Lyer stimuli as they viewed them until they thought that they were ready to make a size judgment. After bimodal exposure, the stimuli were covered and subjects were asked to use their left hands to adjust the ruler behind the panel. The method for obtaining size estimates differed from haptics, since subjects were not permitted to go back and forth from the stimuli to the tangible ruler, as in experiment 2. This method was adopted to ensure that exposure was bimodal, and the stimulus was covered and removed once subjects indicated that they were ready to make their size judgments. If subjects had been permitted to continue making size estimates after they had felt and viewed the stimuli, their exposure would have been purely visual. Clearly, the subjects could not have continued to feel the stimuli with two index fingers while looking at them and simultaneously make ruler adjustments with their left hands. It was thought that this continued visual availability of the stimuli could bias the subjects toward sight.

The results of this condition are shown in table 8. In terms of percentage illusionstrength scores, the strength of the illusion seemed intermediate between vision and touch. However, the illusion was especially weak for the largest stimuli, and this may be consistent with the idea that multimodal input may facilitate veridical perception and reduce illusory misperception. The wings-out stimuli $(M=5.1 \mathrm{~cm})$ were judged as longer than the wings-in patterns $(M=4.67 \mathrm{~cm})$, with the plain lines $(M=5.0 \mathrm{~cm})$ and lines with vertical endings $(M=4.8 \mathrm{~cm})$ judged as intermediate in length. An ANOVA on size estimates showed that the effect of line ending was significant $\left(F_{3,33}=3.489\right.$, $p=0.027)$. A second ANOVA on signed error scores yielded an identical outcome. Wings-in patterns $\left(M_{\mathrm{se}}=-1.68\right)$ were judged as smaller than wings-out Müller-Lyer stimuli $\left(M_{\mathrm{se}}=-1.24\right)$; plain lines $\left(M_{\mathrm{se}}=-1.39\right)$ were judged similar in size to the lines with vertical endings $\left(M_{\mathrm{se}}=-1.51\right)$. The effect of size was highly significant $\left(F_{3,33}=226.7, p<0.001\right)$, but the interaction between size and trials failed to reach significance $(p=0.07)$.

Table 8. Mean size judgments, mean signed error scores (in brackets, beneath mean size judgments), and illusion strength for the Müller-Lyer illusion as a function of figure and size (with standard deviations in parentheses) for bimodal touch (with two index fingers) and vision.

\begin{tabular}{|c|c|c|c|c|c|}
\hline \multirow{2}{*}{$\begin{array}{l}\text { Actual stimulus } \\
\text { size } / \mathrm{cm}\end{array}$} & \multicolumn{4}{|c|}{ Mean size judgment of stimulus/cm } & \multirow{2}{*}{$\begin{array}{l}\text { Illusion } \\
\text { strength } / \%\end{array}$} \\
\hline & wings in & wings out & $\begin{array}{l}\text { vertical } \\
\text { ends }\end{array}$ & $\begin{array}{l}\text { plain } \\
\text { lines }\end{array}$ & \\
\hline 2.5 & $\begin{array}{l}2.51(1.07) \\
{[0.01]}\end{array}$ & $\begin{array}{l}2.95(0.93) \\
{[0.45]}\end{array}$ & $\begin{array}{l}2.72(0.83) \\
{[0.22]}\end{array}$ & $\begin{array}{l}2.65(0.75) \\
{[0.15]}\end{array}$ & 17.6 \\
\hline 5.1 & $\begin{array}{l}3.72(0.98) \\
{[-1.38]}\end{array}$ & $\begin{array}{l}4.53(1.30) \\
{[-0.58]}\end{array}$ & $\begin{array}{l}4.27(1.13) \\
{[-0.83]}\end{array}$ & $\begin{array}{l}3.99(0.94) \\
{[-1.11]}\end{array}$ & 15.9 \\
\hline 7.6 & $\begin{array}{l}5.41(1.45) \\
{[-2.19]}\end{array}$ & $\begin{array}{l}5.78(1.26) \\
{[-1.82]}\end{array}$ & $\begin{array}{l}5.62(1.28) \\
{[-1.98]}\end{array}$ & $\begin{aligned} & 5.60(1.13) \\
& {[-2.00] }\end{aligned}$ & 4.9 \\
\hline 10.2 & $\begin{array}{l}7.03(1.43) \\
{[-3.17]}\end{array}$ & $\begin{array}{l}7.18(1.38) \\
{[-3.02]}\end{array}$ & $\begin{array}{l}7.22(1.83) \\
{[-2.98]}\end{array}$ & $\begin{array}{l}7.14(1.61) \\
{[-3.06]}\end{array}$ & 1.5 \\
\hline
\end{tabular}


In an additional ANOVA on size judgments we compared the results of bimodal exposure to the visual group of experiment 7 (left-hand-ruler group), and failed to find an effect of modality $(F<1)$. A similar pattern of illusory judgments was obtained, with a significant effect of wing endings $(p<0.001)$. The size by mode interaction failed to reach significance $(F<1)$, but the effect of size was highly significant $(p<0.001)$. All of the other main effects and interactions failed to reach significance (all $p s>0.15$ ). An ANOVA on signed error scores yielded identical results.

Despite some concerns that were previously mentioned, a further ANOVA on size estimates was used to compare the two-hand haptic data from experiment 2 with the visual data of experiment 7 (left hand for size estimates). The effect of modality was non-significant $(F<1)$, and the interaction between line ending and modality also failed to reach significance $\left(F_{3,66}=1.04, p=0.38\right)$. The interaction between trials and modality failed to reach significance $(p=0.17)$, and all of the other interactions with modality were non-significant (all $p \mathrm{~s}>0.379$ ). An analysis of signed error scores yielded results that were similar to the ANOVA on size judgments. Visual exposure to the stimuli $\left(M_{\mathrm{se}}=-0.66\right)$ was similar to the effect of haptic exposure $\left(M_{\mathrm{se}}=-0.85\right)$. The effect of modality failed to reach significance $(F<1)$, as did the interaction between modality and trials $\left(F_{1,22}=1.9, p>0.17\right)$. All of the other interactions with modality failed to reach significance (all $F \mathrm{~s}<1$ ). The presence of the illusion was shown by a robust effect of line endings $\left(F_{3,66}=20.6, p<0.001\right)$. However, there was an interesting interaction between size and wing direction $\left(F_{9,198}=46.6, p<0.001\right)$. Tests of simple effects of this interaction showed that the illusion was not present for the largest, $10.2 \mathrm{~cm}$ stimuli $\left(F_{3,66}=2.01, p>0.11\right)$. All of the other tests of simple effects were significant (all $p \mathrm{~s}<0.01$ ). The haptic Müller-Lyer illusion is clearly size-dependent, since it was not found for the largest, $10.2 \mathrm{~cm}$ stimuli.

The present bimodal condition may have actually biased subjects towards touch, since the response measure involved a haptic size estimate, as did the other modality conditions. Thus, one could argue that the visual condition was not purely visual. Future research will be directed towards clarification of this issue, since the response modality matters in multimodal discrepancies between vision and touch (see Heller et al 1999). In future research, it will be necessary to more fully control stimulus presentation conditions to make them properly comparable for vision, touch, and bimodal presentations. It is important that bimodal performance was very similar to that obtained with vision. In addition, performance was not all that different from the two-index-finger touch condition of experiment 2. These results suggest that vision and touch may show similar responses to the Müller-Lyer illusion under conditions of optimal haptic exploration.

\section{General discussion}

The results of the present experiments suggest that the haptic Müller-Lyer illusion is strongly influenced by the manner in which subjects explore stimuli. Experiment 1 showed that the illusion is attenuated when stimuli are traced with a single index finger, and strengthened when grasping or measuring methods are used. The use of two index fingers of two hands further weakened the illusion in experiment 2, and what minimal perceptual distortion that remained was limited to slight enlargement of the wings-out patterns. It is possible that subjects were still responding to the overall global size of the patterns, since the wings-out stimuli were judged as slightly larger than the wings-in and the control stimuli. Moreover, wing length mattered for the smallest stimuli in experiment 6.

Why did the use of two index fingers weaken the illusion in experiment 2? Two related explanations are offered. The use of two fingers of two hands may have encouraged subjects to more adequately explore the stimuli, and thereby perceive them 
more accurately. On a related note, the size of patterns is judged in relation to an egocentric frame of reference (see Millar and Al-Attar 2002), and bimanual exploration at the midline encourages this. Thus, one's elbows may be in contact with one's torso while the two hands feel stimuli, and this allows subjects to relate the size of external stimuli to the body itself.

The results of these experiments bear on issues of intersensory equivalence, the ecological theoretical perspective, and the idea that touch may be a 'reality sense' (see Heller et al 1999). Touch may yield more accurate perception of extent, and slightly less illusory distortion, but this is very much dependent upon the manner in which patterns are examined by touch. Vision may induce stronger or weaker illusions than touch, but this relationship alters as a function of haptic exploration style and stimulus size. The use of grasping and measuring were not optimal strategies, since they magnified the difference between judgments of the wings-in and wings-out stimuli. Note that wing length did not substantially alter the Müller-Lyer illusion for the largest stimuli in touch, but it does this in vision (see DeLucia et al 1994). Perhaps vision yields a more immediate impression of global size, but touch may be less susceptible to this effect as the stimuli increase in extent. In terms of percentage illusion strength, the effects of wing size seem most obvious for the smallest stimuli (see table 6). Certainly, subjects using vision are more likely to apprehend larger stimuli in a single glance. The field of view is clearly much larger for the eyes than the fingers of two hands, and one can see large extents in a single glance. Subjects using haptics are forced to engage in sequential exploration when stimuli are much larger than can be felt with two hands at once or with two arms.

The critical variable for the haptic Müller-Lyer illusion may be the size of one's fingertips. As the size of the wings increases beyond this, wing exploration becomes sequential, rather than simultaneous. This relationship holds when the size of the wings increases beyond that of the fingertip. Once a critical size is reached, further increases in the size of the wings do not seem to greatly alter the strength of the illusion for larger stimuli. Perhaps any effect of increased wing length may also depend upon other configurational factors, namely the angle of the wings or their shapes (Predebon 1996). In experiment 6 , we failed to find a large effect of wing length on the haptic illusion, and the effects that were found appeared in the signed error data and were size-dependent. The effect of increases in wing length were greatest for the smallest, $5.1 \mathrm{~cm}$ stimuli. Perhaps this derived from the sequential nature of haptic exploration and the restriction of haptics to tracing with the index finger in experiment 6 . The effect of wing length for the $5.1 \mathrm{~cm}$ stimuli would be consistent with global-size explanations of the haptic Müller-Lyer illusion. The present results cannot rule out an explanation of the illusion in terms of global size, and further research is required to clarify these issues.

The haptic illusion varied in intensity in a manner that was very dramatic, since percentage illusion-strength scores ranged from $92 \%$ with measuring and small stimuli (experiment 1) to less than $2 \%$ for the largest stimuli and exploration with two index fingers (experiment 2). There are indications in the data that the illusion may be nearly eliminated with the use of two hands for the $10.2 \mathrm{~cm}$ stimuli. The haptic Müller-Lyer illusion was either stronger than the visual illusion, or weaker, depending upon stimulus size and the mode of exploration. When subjects adopt inefficient methods for feeling patterns, the illusion may be magnified, as in grasping, measuring, and the free exploration conditions in experiment 1 . The use of two index fingers produced results in haptics that were closer to those that are found in vision. The haptic illusion in experiment 2 was somewhat weaker than the visual illusion in experiment 7, but this was clearest for all but the smallest stimuli.

The results of experiment 5 failed to show an effect of increases in the thickness of the shaft of the Müller-Lyer stimuli. This would not have been predicted by a confusion 
model, which would have led one to expect that factors that make it easier to discriminate the line shaft from the wings should reduce the strength of the illusion. Moreover, the effect of exploration mode on the illusion appeared limited to the wings-out stimuli in the first two experiments.

The haptic Müller-Lyer illusion differs from the haptic horizontal-vertical illusion in susceptibility to manipulations of stimulus variables, especially size, position in space, and orientation (also see Gentaz and Hatwell 2004). This suggests that different causal mechanisms are at work in the two haptic illusions. The Müller-Lyer illusion was not especially dependent upon a particular spatial placement, but this is not the case for the haptic horizontal-vertical illusion (Heller et al 2003a). The haptic horizontalvertical illusion is stronger with larger stimuli, since the expression of the illusion is frequently caused by radial scanning, with larger movements yielding a stronger illusion. Unlike the haptic horizontal-vertical illusion, the haptic Müller-Lyer illusion was stronger for smaller patterns. Placement of the patterns in an oblique orientation intensified the Müller-Lyer illusion when the stimuli were at an angle of $-45^{\circ}$ from the straight-ahead. The effect of position was not comparable to that for the horizontalvertical illusion, where frontal placement dramatically altered judgments of extent (Heller et al 2003a) and caused a reversal in judged extent of verticals and horizontals. In the horizontal-vertical illusion, placement on the table top yields overestimation of verticals with respect to horizontals. The frontal placement reverses this and produces overestimation of horizontals with respect to verticals. Frontal placement had no effect on the Müller-Lyer illusion in the present study. Note that haptic Müller-Lyer stimuli were judged as larger when vertical, but flat on a table top. These results suggest that some 2-D depictions of haptic space may be judged rather differently in touch than in vision, since one does not find identical effects in the sense of sight.

There are practical implications of the present results for blind people and their examination of tangible graphics. Simply presenting haptic maps to blind or sighted persons could produce misperception, depending upon the method chosen to feel raised-line configurations. The consequences of this strong haptic illusion could be failures to accurately perceive extents in tangible maps or graphics. Even plain lines were often misjudged in the present experiments, and illusory misperception reached very high levels when stimuli were small and subjects were allowed free exploration of the Müller-Lyer stimuli.

Blind people often make use of tangible maps when learning about new geographic environments. The effective use of maps for obtaining information about the world requires that one understand the relationship between one's self and the map. The ability to accurately judge directions in the world depends upon obtaining an accurate spatial metric from the map, and then using this information to compute directions in the world. If the individual makes large errors in judging extents within a tangible display, this could be reflected in errors judging where things are in real space, when the person tries to transfer knowledge about the 2-D display to large-scale space. Thus, tracing with a single index finger reduced the strength of the Müller-Lyer illusion, and the use of two index fingers practically eliminated it, especially for larger stimuli. Measuring produced size estimates that were closest to true size for control stimuli. Maps include lines that intersect at right angles, acute angles, or obtuse angles, and may contain haptic Müller-Lyer stimuli (see Millar and Al-Attar 2002). Measuring might be an effective strategy for feeling simple straight-line extents that terminate in T-shaped junctions. However, a different strategy is probably appropriate when lines intersect and intersecting lines end in acute angles and wing-like configurations. Here, the use of two index fingers of two hands is likely to yield less perceptual distortion. This should be considered when making suggestions about the 'best' exploration methods for the haptic examination of tangible graphics by blind persons. 
Acknowledgments. This research was supported in part by NSF grant BCS-0317293 from the program in Perception, Action and Cognition. We are grateful to Erin Sieving and Lindsey Mitts for assistance with data collection.

\section{References}

Appelle S, Countryman M, 1986 "Eliminating the haptic oblique effect: influence of scanning incongruity and prior knowledge of the standards" Perception 15 325-329

Ballesteros S, Manga D, Reales J M, 1997 "Haptic discrimination of bilateral symmetry in twodimensional and three-dimensional unfamiliar displays" Perception \& Psychophysics $5937-50$

Ballesteros S, Millar S, Reales J M, 1998 "Symmetry in haptic and in visual shape perception" Perception \& Psychophysics $60389-404$

Carrasco M, Figueroa J G, Willen J D, 1986 "A test of the spatial-frequency explanation of the Müller-Lyer illusion" Perception $15553-562$

Coren S, Girgus J S, 1978 Seeing is Deceiving: The Psychology of Visual Illusions (Hillsdale, NJ: Lawrence Erlbaum Associates)

DeLucia P R, 1993 "A quantitative analysis of illusion magnitude predicted by several averaging theories of the Müller-Lyer illusion" Perception \& Psychophysics 50 $498-504$

DeLucia P R, Longmire S P, Kennish J, 1994 "Diamond-winged variants of the Müller-Lyer figure: A test of Virsu's (1971) centroid theory" Perception \& Psychophysics 55 287-295

Dewar R E, 1967 "Sex differences in the magnitude and practice decrement of the Müller-Lyer illusion" Psychonomic Science $9345-346$

Fisher G H, 1970 "An experimental and theoretical appraisal of the perspective and sizeconstancy theories of illusions" Quarterly Journal of Experimental Psychology 22 631-652

Gentaz E, Hatwell Y, 2004 "Geometrical haptic illusions: The role of exploration in the MüllerLyer, vertical-horizontal, and Delboeuf illusions" Psychonomic Bulletin \& Review 1131 - 40

Gibson J J, 1966 The Senses Considered as Perceptual Systems (Boston, MA: Houghton Mifflin)

Gibson J J, 1979 The Ecological Approach to Visual Perception (Boston, MA: Houghton Mifflin)

Hatwell Y, 1960 "Étude de quelques illusions géometriques tactiles chez les aveugles" L'Année Psychologique $6011-27$

Heller M A, 1992 "The effect of orientation on tactual braille recognition: Optimal 'touching positions" "Perception \& Psychophysics $51549-556$

Heller M A, Brackett D D, Salik S S, Scroggs E, Green S, 2003a "Objects, raised-lines and the haptic horizontal - vertical illusion" Quarterly Journal of Experimental Psychology A 56891 - 907

Heller M A, Brackett D D, Wilson K, Yoneyama K, Boyer A, Steffen H, 2002a "The haptic Müller-Lyer illusion in sighted and blind people" Perception 31 1263-1274

Heller M A, Brackett D D, Wilson K, Yoneyama K, Boyer A, 2002b "Visual experience and the haptic horizontal - vertical illusion" British Journal of Visual Impairment 20 105-109

Heller M A, Calcaterra J A, Burson L L, Green S L, 1997 "The tactual horizontal-vertical illusion depends on radial motion of the entire arm" Perception \& Psychophysics 59 1297-1331

Heller M A, Calcaterra J A, Green S L, Brown L, 1999 "Intersensory conflict between vision and touch: The response modality dominates when precise, attention-riveting judgments are required" Perception \& Psychophysics $611384-1398$

Heller M A, Hasselbring K, Wilson K, Shanley M, Yoneyama K, 2004 "Haptic illusions in the sighted and blind", in Touch, Blindness and Neuroscience Eds S Ballesteros, M A Heller (Madrid: UNED Press) pp 135-144

Heller M A, Wilson K, Schultz J, Greene J, Shanley M, Sieving E, 2003b "Exploration mode and the haptic Müller-Lyer illusion", presented at the 44th Annual Meeting of the Psychonomic Society, Vancouver, BC, November

Jansson G, Monaci L, 2004 "Haptic identification of objects with different numbers of fingers", in Touch, Blindness and Neuroscience Eds S Ballesteros, M A Heller (Madrid: UNED Press) pp $209-219$

Millar S, 1984 "Is there a 'best hand' for braille?" Cortex $2075-87$

Millar S, 1994 Understanding and Representing Space: Theory and Evidence from Studies with Blind and Sighted Children (Oxford: Clarendon Press)

Millar S, 1997 Reading by Touch (Oxford: Oxford University Press)

Millar S, Al-Attar Z, 2002 "The Müller-Lyer illusion in touch and vision: Implications for multisensory processing" Perception \& Psychophysics $64353-365$

Over R, 1966 "A comparison of haptic and visual judgments of some illusions" American Journal of Psychology $79590-595$

Predebon J, 1996 "The role of the angle components in the wings-in and wings-out forms of the Müller-Lyer illusion" Perception 25773 - 781 
Rudel R G, Teuber H L, 1963 "Decrement of the visual and haptic Müller-Lyer illusion on repeated trials: A study of crossmodal transfer" Quarterly Journal of Experimental Psychology $15125-131$

Symmons M, Richardson B, 2000 "Raised line drawings are spontaneously explored with a single finger" Perception $29621-626$ 


\section{PERCEPTION}

VOLUME 352006

www.perceptionweb.com

Conditions of use. This article may be downloaded from the Perception website for personal research by members of subscribing organisations. Authors are entitled to distribute their own article (in printed form or by e-mail) to up to 50 people. This PDF may not be placed on any website (or other online distribution system) without permission of the publisher. 